\title{
Gamma, Fast Neutron, Proton, and Alpha Shielding Properties of Borate Glasses: A Closer Look on Lead (II) Oxide and Bismuth (III) Oxide Reinforcement
}

\author{
Ghada ALMisned ${ }^{1}$, Huseyin O. Tekin ${ }^{2,3}$, Esra Kavaz ${ }^{4}$, Ghaida Bilal ${ }^{2,5}$, Shams A.M. Issa ${ }^{6,7}$, \\ Hesham M.H. Zakaly ${ }^{7,8, *(\mathbb{D})}$ and Antoaneta Ene ${ }^{9, *(\mathbb{D})}$
}

\section{check for}

updates

Citation: ALMisned, G.; Tekin, H.O.; Kavaz, E.; Bilal, G.; Issa, S.A.M.; Zakaly, H.M.H.; Ene, A. Gamma, Fast Neutron, Proton, and Alpha Shielding Properties of Borate Glasses: A Closer Look on Lead (II) Oxide and Bismuth (III) Oxide Reinforcement. Appl. Sci. 2021, 11, 6837. https://doi.org/10.3390/ app11156837

Academic Editor: Richard Kouzes

Received: 17 June 2021

Accepted: 22 July 2021

Published: 25 July 2021

Publisher's Note: MDPI stays neutral with regard to jurisdictional claims in published maps and institutional affiliations.

Copyright: (c) 2021 by the authors. Licensee MDPI, Basel, Switzerland. This article is an open access article distributed under the terms and conditions of the Creative Commons Attribution (CC BY) license (https:/ / creativecommons.org/licenses/by/ $4.0 /)$.
1 Department of Physics, College of Science, Princess Nourah Bint Abdulrahman University, Riyadh 11564, Saudi Arabia; gaalmisned@pnu.edu.sa

2 Department of Medical Diagnostic Imaging, College of Health Sciences, University of Sharjah, Sharjah 27272, United Arab Emirates; htekin@sharjah.ac.ae (H.O.T.); u17104268@sharjah.ac.ae (G.B.)

3 Medical Radiation Research Center (USMERA), Uskudar University, 34672 Istanbul, Turkey

4 Department of Physics, Faculty of Sciences, Ataturk University, 25240 Erzurum, Turkey; esra.kavaz@atauni.edu.tr

5 Center for Advanced Materials Research, Research Institute of Sciences and Engineering, University of Sharjah, Sharjah 27272, United Arab Emirates

6 Department of Physics, Faculty of Science, University of Tabuk, Tabuk 47512, Saudi Arabia; sh_issa@ut.edu.sa

Physics Department, Faculty of Science, Al-Azhar University, Assiut 71452, Egypt

8 Institute of Physics and Technology, Ural Federal University, 620000 Ekaterinburg, Russia

9 INPOLDE Research Center, Department of Chemistry, Physics and Environment, Faculty of Sciences and Environment, Dunarea de Jos University of Galati, 47 Domneasca Street, 800008 Galati, Romania

* Correspondence: h.m.zakaly@gmail.com or h.m.zakaly@azhar.edu.eg (H.M.H.Z.); aene@ugal.ro or Antoaneta.Ene@ugal.ro (A.E.)

Abstract: The purpose of this research was to investigate the shielding characteristics of highamount heavy metal oxide and $\mathrm{Eu}^{3+}$-activated borate glasses based on $10 \mathrm{La}_{2} \mathrm{O}_{3}-50 \mathrm{HMO}-(40-\mathrm{x})$ $\mathrm{B}_{2} \mathrm{O}_{3}-\mathrm{xEu}_{2} \mathrm{O}_{3}\left(\mathrm{x}=0,0.5,1,2\right.$, and $\left.\mathrm{HMO}=\mathrm{PbO}, \mathrm{Bi}_{2} \mathrm{O}_{3}\right)$. Critical gamma radiation attenuation characteristics, particularly mass attenuation coefficients of investigated heavy metal oxide glass samples, were determined using Monte Carlo simulations and the Phy-x/PSD software. Following that, we looked at the half-value layer, mean free path, effective atomic number, and build-up factors across a broad energy range $(0.015-15 \mathrm{MeV})$. According to the study's results, the addition of $\mathrm{Eu}_{2} \mathrm{O}_{3}$ enhanced the mass attenuation coefficient and effective atomic number, while reducing the half-value layer, mean free path, and accumulation factors. In terms of gamma radiation attenuation, the LBi50BEu glass system surpassed the LPb50BEu glass system in terms of overall shielding properties against nuclear radiation. Additionally, the heavy metal oxide glass' efficacy as a neutron shield was determined using fast neutron removal cross-sections $\left(\Sigma_{R}\right)$. LBi50BEu2 glass was shown to be more effective in preventing the penetration of charged particle radiation.

Keywords: HMO glasses; nuclear radiation shielding; glasses; MCNPX

\section{Introduction}

With today's extensive use of radiation sources and radioactive materials, it is extremely essential to use radiation sources cautiously and safely. Against gamma radiation, the most utilized shielding materials are lead $(\mathrm{Pb})$ and lead-equivalent compounds. However, $\mathrm{Pb}^{\prime}$ s negative impacts on human health and the environment pose a serious concern. Subsequently, it has some disadvantageous material properties, such as optical non-transparency, low durability, high cost, and material durability in terms of shielding applications [1]. Another material used to attenuate gamma radiation is concrete. Its most serious shortcomings, however, are that it is exceedingly heavy, pricey, opaque, and cracks when overused [2]. In recent years, researchers have been attempting to investigate the 
features of eco-friendly, very dense, and chemically homogeneous materials that could be utilized as a replacement for concrete and lead. Corrosion-resistant, biocompatible radiation shielding systems must be created that can be modelled into narrow, compact forms with outstanding structural integrity and endurance. Glass has been proven to be an efficient shielding material due to its transparency to visible light, ease of production, and ease of property change through composition and preparation techniques. Glasses are one of a kind in that they can handle a wide variety of elements. They can act as a shield against hazardous ionizing radiation because of this characteristic. Impurities in the form of metals were incorporated into regular glass to transform it into a radiation shield glass. This doping, especially with heavy metal oxides $(\mathrm{Ba}, \mathrm{Bi}, \mathrm{Pb})$, enhances the glass' attenuation properties, making it ideal for shielding applications. Glass formers are oxides that serve as the structural backbone of the glass network and are needed for optimal operation. As potential substitutes, borate glasses and lead-free compounds with adequate chemical resistance, transparency, and radiation protection are being investigated [3]. Borate-based glasses have a higher melting point and resistance to temperature changes than other types of glasses. Because of their high solubility of rare earth ions, ease of mass production, and low cost, bore-based glasses are the greatest choice for developing new optical devices. Borate-based glass systems have good broad-band properties and demonstrate significant increases in luminescence intensity. Doping transition metal and rare earth ions into borate glasses improves optical transmittances, electric conductivities, thermal, and even magnetic characteristics [4-6]. Pb-based glasses are particularly fascinating due to their strong electrical conductivity, stability, and wide glass-forming range. Strong UV transmittances, low melting and glass transition temperatures, and great thermal stability are all advantages of Pb-based glasses [7,8]. According to a study conducted by Tekin et al. [9], phosphate-based glasses are ideal for the fabrication of optical fibres and shielding material for radiation detection, among many other applications. Agar et al. [10] conducted another significant study which revealed that doping glasses with erbium (Er) leads to an increase in the mass attenuation coefficient and a decrease in build-up factors and half-value layer. Subsequently, glasses doped with Er possess significant radiation-shielding properties. The goal of this novel study is to determine the nuclear-radiation-shielding properties of glass samples from the 10La2O3-50HMO- $(40-\mathrm{x}) \mathrm{B}_{2} \mathrm{O}_{3}-\mathrm{xEu}_{2} \mathrm{O}_{3}(\mathrm{x}=0,0.5,1$ and $2 \mathrm{~mol}$ percent and $\mathrm{HMO}=\mathrm{PbO}, \mathrm{Bi}_{2} \mathrm{O}_{3}$ ) system in a wide range of energies between 0.015 and $15 \mathrm{MeV}$ using the MCNPX (version 2.7.0) general-purpose Monte Carlo code [11] and Phy-X/PSD [12] software. It also aims to establish the materials' mechanical qualities, as well as their suitability as shielding materials. The results of this study will be useful in the field of glass literature, notably in the field of radiation shielding. Researchers will gain a better understanding of the utility of HMO-doped glasses as nuclear-radiation-shielding materials as a result of the findings of this study.

\section{Materials and Methods}

In this research, eight different high amount $\mathrm{HMO}\left(\mathrm{PbO}\right.$ and $\left.\mathrm{Bi}_{2} \mathrm{O}_{3}\right)$-added and $\mathrm{Eu}^{3+}$-activated borate glass samples [13] were extensively investigated in terms of their radiation-shielding properties (see Table 1). The densities of the glass samples were reported as follows:

- $5.393 \mathrm{~g} / \mathrm{cm}^{3}-\mathrm{LPb} 50 \mathrm{~B}$;

- $\quad 5.36 \mathrm{~g} / \mathrm{cm}^{3}-\mathrm{LPb} 50 \mathrm{Eu} 0.5$;

- $\quad 5.103 \mathrm{~g} / \mathrm{cm}^{3}$-LPb50BEu1;

- $\quad 5.043 \mathrm{~g} / \mathrm{cm}^{3}-\mathrm{LPb} 50 \mathrm{BEu} 2$;

- $\quad 6.812 \mathrm{~g} / \mathrm{cm}^{3}-\mathrm{LBi} 50 \mathrm{~B}$;

- $\quad 6.795 \mathrm{~g} / \mathrm{cm}^{3}-\mathrm{LBi} 50 \mathrm{Eu} 0.5$;

- $\quad 5.808 \mathrm{~g} / \mathrm{cm}^{3}$-LBi50Eu1;

- $\quad 5.940 \mathrm{~g} / \mathrm{cm}^{3}-\mathrm{LBi} 50 \mathrm{Eu} 2$. 
Table 1. Chemical compositions and density for glass samples.

\begin{tabular}{|c|c|c|c|c|c|c|c|c|c|c|c|c|}
\hline \multirow{2}{*}{$\begin{array}{l}\text { Sample } \\
\text { Code }\end{array}$} & \multicolumn{5}{|c|}{$\mathrm{mol} \%$} & \multicolumn{6}{|c|}{$\mathbf{w t} \%$} & \multirow{2}{*}{$\underset{\left(\mathrm{g} / \mathrm{cm}^{3}\right.}{\rho}$} \\
\hline & $\mathrm{La}_{2} \mathrm{O}_{3}$ & $\mathrm{PbO}$ & $\mathrm{Bi}_{2} \mathrm{O}_{3}$ & $\mathrm{~B}_{2} \mathrm{O}_{3}$ & $\mathrm{Eu}_{2} \mathrm{O}_{3}$ & B & O & La & Eu & $\mathrm{Pb}$ & $\mathrm{Bi}$ & \\
\hline LPb50B & 10 & 50 & - & 40 & 0 & 0.0503 & 0.1860 & 0.1615 & 0 & 0.6022 & - & 5.393 \\
\hline LPb50Eu0.5 & 10 & 50 & - & 39.5 & 0.5 & 0.0492 & 0.1845 & 0.1602 & 0.0088 & 0.5973 & - & 5.36 \\
\hline LPb50BEu1 & 10 & 50 & - & 39 & 1 & 0.0482 & 0.1830 & 0.1589 & 0.0174 & 0.5925 & - & 5.103 \\
\hline LPb50BEu2 & 10 & 50 & - & 38 & 2 & 0.0462 & 0.1801 & 0.1564 & 0.0342 & 0.5831 & - & 5.043 \\
\hline LBi50B & 10 & - & 50 & 40 & 0 & 0.0295 & 0.1636 & 0.0947 & 0 & - & 0.7123 & 6.812 \\
\hline LBi50Eu0.5 & 10 & - & 50 & 39.5 & 0.5 & 0.0290 & 0.1628 & 0.0942 & 0.0052 & - & 0.7088 & 6.795 \\
\hline LBi50BEu1 & 10 & - & 50 & 39 & 1 & 0.0285 & 0.1620 & 0.0938 & 0.0103 & - & 0.7055 & 5.808 \\
\hline LBi50BEu2 & 10 & - & 50 & 38 & 2 & 0.0275 & 0.1605 & 0.0929 & 0.0203 & - & 0.6988 & 5.94 \\
\hline
\end{tabular}

\subsection{Studied Radiation Shielding Parameters}

Equation (1) describes the photon flux attenuation in narrow photon beam. As indicated in Equation (1), a connection exists between the radiation intensity $(I)$ and the absorbent glass material's thickness $(t)$, as well as the radiation intensity $\left(I_{0}\right)$ prior to contacting the substance [14]:

$$
I=I_{o} e^{-\mu t}
$$

In Equation (1), $\mu$ is the linear attenuation coefficient.

The term of mass attenuation coefficient $\left(\mu_{m}\right)$ is a measure of how likely incident photons are to interact with matter per unit density. The formula shown in Equation (2) is used to compute it:

$$
\mu_{m}=\sum_{i} w_{i}\left(\frac{\mu}{\rho}\right)_{i}
$$

where $\left(\mu_{m}\right)$ is the mass attenuation coefficient, $\left(w_{i}\right)$ is the weight fraction of the $i$ th constituent element, $(\mu)$ is the linear attenuation coefficient, and $(\rho)$ is the density. The mean free path $(M F P)$ is the mean distance travelled by a photon inside a shielding material prior to encountering an interaction. It is calculated using the following Equation (3):

$$
M F P=\frac{1}{\mu}
$$

The half-value layer $(H V L)$ is the absorber thickness required to reduce the radiation intensity to half of its starting value, as determined by Equation (4):

$$
H V L=\frac{\ln (2)}{\mu}
$$

In composite materials, the term "effective atomic number" $\left(Z_{\text {eff }}\right)$ cannot be stated as a single number; instead, it varies depending on the material and specific characteristics of the interacting radiation, and it provides information about the material. The direct method was used to compute the $Z_{\text {eff }}$ values of the samples in this investigation:

$$
Z_{e f f}=\frac{\Sigma_{i} f_{i} A_{i}\left(\frac{\mu}{\rho}\right)_{i}}{\Sigma_{j} f_{j}\left(\frac{A_{j}}{Z_{j}}\right)\left(\frac{\mu}{\rho}\right)_{j}}
$$

In Equation (5), $f_{i}$ is fraction by mole, $A_{i}$ is atomic weight, and $Z_{j}$ is atomic number of $i$ th constituent element. When developing gamma radiation shielding, build-up factor (BUF) considerations are crucial. The energy absorption build-up factor (EABF) is a measure of the amount of time a material is exposed to air after it has been penetrated by a particle. The exposure build-up factor (EBF) is a measurement of the amount of exposure in air after it has passed through the shielding material. BUFs are often computed using the geometric progression (G-P) fitting technique, which is described in detail below. To begin, the equivalent atomic number $\left(Z_{e q}\right)$ of a particular energy is determined by comparing 
its $\left(\mu_{m}\right)$ Compton $/\left(\mu_{m}\right)$ total ratio to the element's convenient ratio. In this study, the $Z_{\mathrm{eq}}$ values for the glasses were determined using the interpolation technique. The EBF and EABF values for a single-layered gamma-ray-shielding enclosure (GSE), with an OT of up to $100 \mathrm{mfp}$ and an energy range of 0.015 to $15 \mathrm{MeV}$, are calculated using the following Equations (6)-(8).

$$
\begin{gathered}
B(E, X)=1+\frac{b-1}{K-1}\left(K^{x}-1\right) \text { for } K \neq 1 \\
B(E, X)=1+(b-1) x \text { for } K=1 \\
K(E, x)=c x^{a}+\frac{d \tanh \frac{x}{X_{k}-2}-\tanh (-2) 1-\tanh (-2)}{1-\tanh (-2)} \text { for } x \leq 40 \mathrm{mfp}
\end{gathered}
$$

In the above equations:

$E$ : Incoming photon energy;

$X$ : Penetration depth in millimetres per second;

$B$ : Accumulation factor at 1 millimetre per second;

$K$ : Photon-dose multiplication factor.

The projected range is a critical parameter for analysing the shielding and interaction of nuclear radiation with different objects at different protons and alpha kinetic energies. The predicted range provides an explanation for the mean value of the depth at which alpha and proton particles begin to slow down and come to rest. The stopping power of a vehicle is defined as the quantity of energy lost over a certain distance. The mass stop power of a system is the amount of energy lost per unit of density. For the computation of ion deposition data in ion irradiation materials, the Stopping and Range of Ions in Materials (SRIM) equation was utilized, and Monte Carlo simulations were utilized for the computation of data using the SRIM equation. According to the findings of this study, attenuation characteristics of the glass produced were tested against charged particles, such as alpha and proton, with the results measured in terms of alpha/proton mass stopping power and alpha/proton projected range [15]. The last term to discuss is "effective neutron removal" $(R)$, which refers to the process of removing neutrons from the material in a timely way. Following the definition of the cross-defined (or un-scattered) cross-section definition, the total amount of nuclear energy generated in a fission event from the first (or fast) neutron is equal to the average anticipated quantity of nuclear energy generated in a fission event. Calculating the $\mathrm{R}$ values of a material may be accomplished using the following Equation (9):

$$
\Sigma_{R / \rho}=\sum w_{i}\left(\Sigma_{R / \rho}\right)
$$

In Equation (9), $\Sigma_{R / \rho}$ is mass removal cross-section $\left(\mathrm{cm}^{2} / \mathrm{g}\right)$, and $w_{i}$ is partial density $\left(\mathrm{g} / \mathrm{cm}^{3}\right)$ of the $i$ th element [16].

\subsection{Monte Carlo Simulations (MCNPX Version 2.7.0)}

The mass attenuation coefficients of the LPbX and LBiX glasses were efficiently estimated using the general-purpose Monte Carlo algorithm MCNPX (version 2.7.0). To begin, input data for MCNPX were created utilizing the basic components as follows:

- Cell card;

- Surface card;

- Source information.

Figure 1a depicts the 3D view of the modelled setup obtained from MCNPX Visual Editor VE VisedX22S. Within a lead $(\mathrm{Pb})$ shield block, a point isotropic gamma-ray source was placed. The glass specimens were then modelled using their elemental compositions (in percent weight) and material densities (in grams per cubic centimetre). The cylindrical form of the glass specimen had a radius of $5 \mathrm{~cm}$ and was made of clear glass. As a consequence of this evolution, the borders of cell cards were filled with the material qualities that were required for their construction (i.e., elemental mass fraction and material density). In Figure 1b, one can see a 2D perspective and the dimensions of the proposed 
MCNPX simulation setup for determining the gamma-ray transmission capabilities of lenses, such as LPbX and LBiX (obtained from MCNPX Visual Editor VE VisedX22S). The modelled point isotropic source may alternatively be viewed as an extension of the overall gamma-ray transmission arrangement in Figure 1a, as can be seen in Figure 1b. Listed in Table 1 are the elemental mass fractions of the $\mathrm{LPbX}$ and LBiX glasses that were under investigation. MCNPX INPUT file, which was used to define the elemental composition of glass specimens, had a Mn variable, which should be noted. The term of Mn is an integral part of material definition of $n$th material, along with constituent elements, their atomic numbers, and their elemental mass fractions (wt.\%). Using the results of the initial cell description procedure, we were able to determine the importance of photon and electron interactions (IMP: p, e) in the cell. LPbX and LBiX glasses were connected to the opposite side of the detector field (F4 Tally Mesh) for the purpose of counting the attenuated gamma rays that were produced. This kind of tally mesh is helpful for estimating the average photon flux in a point or cell, as well as for other applications. A total of $10^{8}$ particles at different photon energies were collected for each glass sample after each run was repeated (i.e., from $0.015 \mathrm{MeV}$ to $15 \mathrm{MeV}$ ). When running all simulations, the MCNPX model exhibited a relative error rate less than 1 percent (\%).

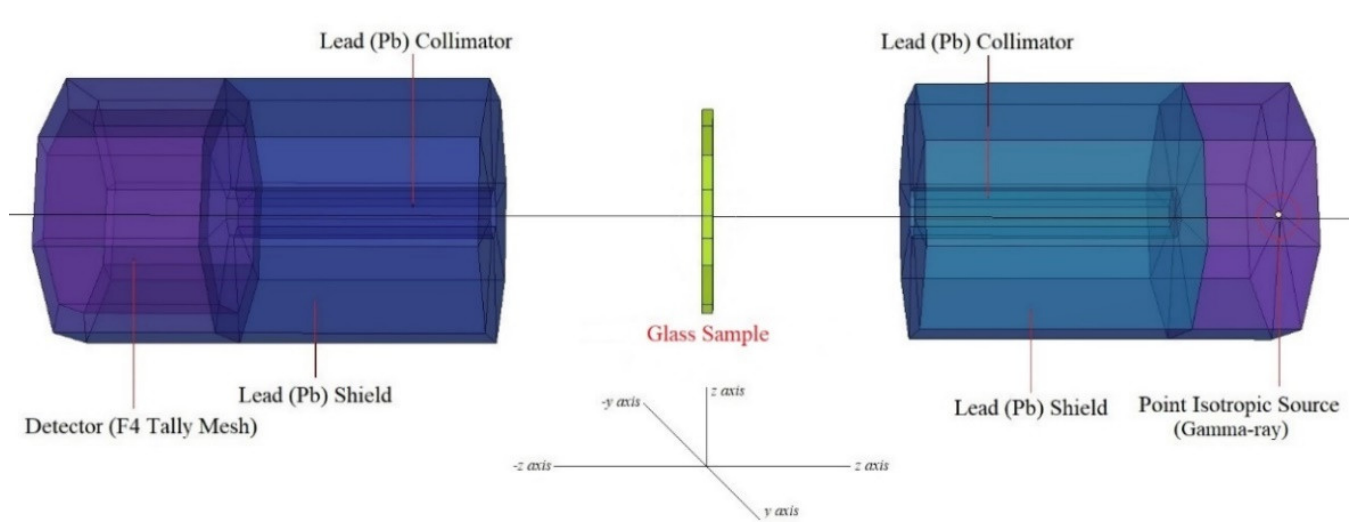

(a)

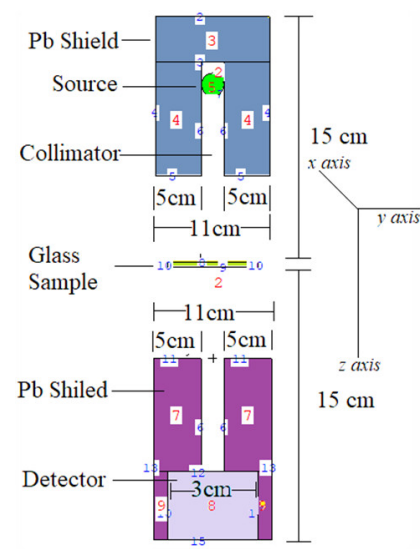

(b)

Figure 1. MCNPX setup: (a) 3D view of gamma-ray transmission setup obtained from MCNPX Visual Editor; (b) 2D view of gamma-ray transmission setup with dimensional information obtained from MCNPX Visual Editor.

\section{Results and Discussions}

In this study, a comprehensive investigation on high-amount heavy metal oxide (HMO)-added and $\mathrm{Eu}^{3+}$-activated borate glasses based on $10 \mathrm{La}_{2} \mathrm{O}_{3}-50 \mathrm{HMO}-(40-\mathrm{x}) \mathrm{B}_{2} \mathrm{O}_{3}-$ $\mathrm{xEu}_{2} \mathrm{O}_{3}\left(\mathrm{x}=0,0.5,1\right.$ and $2 \mathrm{~mol} \%$ and $\left.\mathrm{HMO}=\mathrm{PbO}, \mathrm{Bi}_{2} \mathrm{O}_{3}\right)$ system was carried out in terms of their individual and comprehensive gamma-ray and charged particle attenuation competencies. In total, eight different glass samples, encoded LPb50B, LPb50Eu0.5, LPb50BEu, LPb50BEu2, LBi50B, LBi50Eu0.5, LBi50Eu1, and LBi50Eu2, were classified considering HMO type in their structure. Material densities and chemical properties of the aforementioned glasses can be obtained from Table 1 . It is clearly seen that material densities of PbO-reinforced borate glasses varied from $5.043 \mathrm{~g} / \mathrm{cm}^{3}$ to $5.393 \mathrm{~g} / \mathrm{cm}^{3}$, whereas material densities of $\mathrm{Bi}_{2} \mathrm{O}_{3}$-reinforced borate glasses varied from $5.940 \mathrm{~g} / \mathrm{cm}^{3}$ to $6.812 \mathrm{~g} / \mathrm{cm}^{3}$. In the glass structure, $(40-\mathrm{x}) \mathrm{B}_{2} \mathrm{O}_{3}-\mathrm{xEu}_{2} \mathrm{O}_{3}$ indicates that, in both glass groups, $\mathrm{B}_{2} \mathrm{O}_{3}$ has been replaced with $\mathrm{Eu}_{2} \mathrm{O}_{3}$ from 0 to 2 mole\%. Therefore, one can say that $\mathrm{Bi}_{2} \mathrm{O}_{3}$ contribution (as $50 \%$ mole) has increased the material density more than $\mathrm{PbO}$ contribution in terms of their HMO structures. To begin, we calculated the mass attenuation coefficients (MAC) of the aforementioned glass samples using the MCNPX code, and then compared them to theoretical findings obtained using the Phy-X/PSD program. In Table 2, the findings of both techniques are listed, together with their respective relative variances. Additionally, Figure 2 illustrates the variation in the MAC values of the investi- 
gated glasses throughout the energy range $0.015-15 \mathrm{MeV}$. From Table 2, it is seen that the MAC values of $\mathrm{LPb} 50 \mathrm{~B}$ and $\mathrm{LPb} 50 \mathrm{BEu} 2$ glasses vary between $78.429 \mathrm{~cm}^{2} / \mathrm{g}-0.045 \mathrm{~cm}^{2} / \mathrm{g}$ and $79.045 \mathrm{~cm}^{2} / \mathrm{g}-0.045 \mathrm{~cm}^{2} / \mathrm{g}$, while the MAC values for LBi50B and LBi50Eu2 glasses are between $89.281 \mathrm{~cm}^{2} / \mathrm{g}-0.048 \mathrm{~cm}^{2} / \mathrm{g}$ and $89.442 \mathrm{~cm}^{2} / \mathrm{g}-0.048 \mathrm{~cm}^{2} / \mathrm{g}$. It is noticed from Figure 2 that the MAC values decrease rapidly at $0.015-0.1 \mathrm{MeV}$ photon energies, and increase suddenly before reaching $0.1 \mathrm{MeV}$. This rapid drop is due to the impact of photoelectric absorption (PEA) in the low energy region and the changing in cross-section of interaction with $1 / \mathrm{E}^{3.5}$ in that zone. Besides, a sudden increase occurred around $88.00 \mathrm{keV}$ and $90.52 \mathrm{keV}$, which are the absorption edges of $\mathrm{Pb}$ and Bi heavy elements in two glass systems, since the cross-section of PEA is proportional to $\mathrm{Z}^{4-5}$. It is regarded that the reduction in MAC values is slower at medium energies where the Compton scattering (CS) process $(\mathrm{Z} / \mathrm{E})$ is powerful. It is remarkable that after $1.022 \mathrm{MeV}$, where pair production (PP) occurs, the MAC values increased slowly with increasing energy. At high energy levels, most photons are annihilated, and MAC values vary depending on $Z^{2}$. Therefore, the MAC values of glasses containing $\mathrm{Bi}$ and $\mathrm{Pb}$ elements with high $\mathrm{Z}$ at high energies increased. With the addition of $\mathrm{Eu}_{2} \mathrm{O}_{3}(0,0.5,1,2 \mathrm{~mol} \%)$, the MAC values are obtained at $0.015 \mathrm{MeV}$ as $78.429 \mathrm{~cm}^{2} / \mathrm{g}, 78.586 \mathrm{~cm}^{2} / \mathrm{g}, 78.742 \mathrm{~cm}^{2} / \mathrm{g}$, and $79.045 \mathrm{~cm}^{2} / \mathrm{g}$ and $89.281 \mathrm{~cm}^{2} / \mathrm{g}, 89.322 \mathrm{~cm}^{2} / \mathrm{g}, 89.362 \mathrm{~cm}^{2} / \mathrm{g}$, and $89.442 \mathrm{~cm}^{2} / \mathrm{g}$ for LPb50B and LBi50B glass systems, respectively. From this, it can be deduced that the insertion of $\mathrm{Eu}_{2} \mathrm{O}_{3}$ increases MAC values in both glass systems, and the higher MAC values are obtained in glasses prepared with $\mathrm{Bi}_{2} \mathrm{O}_{3}$. The material thickness of LPb50BEu and LBi50BEu glasses for $0.015-15 \mathrm{MeV}$ photon energies, which halves the incoming radiation intensity, is presented in Figure 3.

Table 2. Obtained mass attenuation coefficients from MCNPX code and Phy-X/PSD program.

\begin{tabular}{|c|c|c|c|c|c|c|c|c|c|c|c|c|c|c|c|c|}
\hline \multirow{2}{*}{$\begin{array}{l}\text { Energy } \\
(\mathrm{MeV})\end{array}$} & \multicolumn{2}{|l|}{$\mathrm{LPb} 50 \mathrm{~B}$} & \multicolumn{2}{|c|}{ LPb50BEu0.5 } & \multicolumn{2}{|c|}{ LPb50BEu1 } & \multicolumn{2}{|c|}{ LPb50BEu2 } & \multicolumn{2}{|l|}{ LBi50B } & \multicolumn{2}{|c|}{ LBi50BEu0.5 } & \multicolumn{2}{|c|}{ LBi50BEu1 } & \multicolumn{2}{|c|}{ LBi50BEu2 } \\
\hline & Phy-X & MCNP & Phy-X & MCNP & Phy-X & MCNP & Phy-X & MCNP & Phy-X & MCNP & Phy-X & MCNP & Phy-X & MCNP & Phy-X & MCNP \\
\hline 0.015 & 78.429 & 81.792 & 78.587 & 81.504 & 78.742 & 80.346 & 79.045 & 81.458 & 89.281 & 90.231 & 89.322 & 90.348 & 89.363 & 90.569 & 89.442 & 90.775 \\
\hline 0.02 & 57.229 & 59.483 & 57.134 & 59.126 & 57.042 & 58.130 & 56.861 & 59.258 & 66.859 & 67.120 & 66.757 & 67.563 & 66.657 & 67.681 & 66.458 & 67.718 \\
\hline 0.03 & 20.038 & 21.589 & 20.001 & 21.359 & 19.965 & 20.561 & 19.894 & 19.992 & 23.511 & 23.746 & 23.473 & 23.874 & 23.435 & 23.991 & 23.360 & 24.016 \\
\hline 0.04 & 12.869 & 13.067 & 12.823 & 12.916 & 12.778 & 12.985 & 12.689 & 12.816 & 13.139 & 13.234 & 13.110 & 13.253 & 13.082 & 13.309 & 13.027 & 13.403 \\
\hline 0.05 & 7.228 & 7.561 & 7.331 & 7.572 & 7.433 & 7.581 & 7.631 & 7.684 & 7.377 & 7.408 & 7.437 & 7.524 & 7.497 & 7.538 & 7.614 & 7.704 \\
\hline 0.06 & 4.514 & 4.689 & 4.578 & 4.701 & 4.641 & 4.704 & 4.765 & 4.771 & 4.611 & 4.651 & 4.649 & 4.772 & 4.686 & 4.784 & 4.759 & 4.771 \\
\hline 0.08 & 2.170 & 2.198 & 2.200 & 2.201 & 2.230 & 2.235 & 2.288 & 2.290 & 2.223 & 2.230 & 2.241 & 2.251 & 2.258 & 2.256 & 2.292 & 2.295 \\
\hline 0.1 & 3.752 & 3.772 & 3.748 & 3.775 & 3.744 & 3.778 & 3.736 & 3.751 & 4.335 & 4.338 & 4.330 & 4.358 & 4.325 & 4.379 & 4.315 & 4.401 \\
\hline 0.15 & 1.378 & 1.380 & 1.376 & 1.377 & 1.374 & 1.381 & 1.371 & 1.384 & 1.587 & 1.593 & 1.585 & 1.604 & 1.583 & 1.612 & 1.579 & 1.615 \\
\hline 0.2 & 0.699 & 0.703 & 0.698 & 0.701 & 0.697 & 0.703 & 0.695 & 0.702 & 0.800 & 0.804 & 0.799 & 0.807 & 0.798 & 0.810 & 0.795 & 0.813 \\
\hline 0.3 & 0.299 & 0.302 & 0.299 & 0.300 & 0.299 & 0.302 & 0.298 & 0.305 & 0.336 & 0.338 & 0.335 & 0.341 & 0.335 & 3.345 & 0.334 & 3.347 \\
\hline 0.4 & 0.183 & 0.185 & 0.183 & 0.185 & 0.183 & 0.185 & 0.182 & 0.185 & 0.201 & 0.203 & 0.201 & 0.203 & 0.200 & 0.204 & 0.200 & 0.205 \\
\hline 0.5 & 0.134 & 0.136 & 0.134 & 0.136 & 0.134 & 0.136 & 0.133 & 0.136 & 0.144 & 0.145 & 0.144 & 0.145 & 0.144 & 0.145 & 0.144 & 0.144 \\
\hline 0.6 & 0.108 & 0.110 & 0.108 & 0.110 & 0.108 & 0.110 & 0.107 & 0.110 & 0.114 & 0.114 & 0.114 & 0.114 & 0.114 & 0.114 & 0.114 & 0.114 \\
\hline 0.8 & 0.081 & 0.095 & 0.081 & 0.095 & 0.081 & 0.095 & 0.081 & 0.095 & 0.084 & 0.084 & 0.084 & 0.084 & 0.084 & 0.084 & 0.084 & 0.084 \\
\hline 1 & 0.067 & 0.071 & 0.067 & 0.071 & 0.067 & 0.071 & 0.067 & 0.071 & 0.069 & 0.070 & 0.069 & 0.070 & 0.069 & 0.070 & 0.069 & 0.069 \\
\hline 1.5 & 0.051 & 0.053 & 0.051 & 0.053 & 0.051 & 0.053 & 0.051 & 0.053 & 0.052 & 0.052 & 0.052 & 0.052 & 0.052 & 0.052 & 0.052 & 0.053 \\
\hline 2 & 0.045 & 0.048 & 0.045 & 0.048 & 0.045 & 0.048 & 0.045 & 0.048 & 0.046 & 0.046 & 0.046 & 0.046 & 0.046 & 0.046 & 0.046 & 0.046 \\
\hline 3 & 0.040 & 0.041 & 0.040 & 0.041 & 0.040 & 0.041 & 0.040 & 0.041 & 0.041 & 0.042 & 0.041 & 0.042 & 0.041 & 0.042 & 0.041 & 0.042 \\
\hline 4 & 0.038 & 0.040 & 0.038 & 0.040 & 0.038 & 0.040 & 0.038 & 0.040 & 0.040 & 0.040 & 0.040 & 0.041 & 0.040 & 0.042 & 0.040 & 0.040 \\
\hline 5 & 0.038 & 0.040 & 0.038 & 0.040 & 0.038 & 0.040 & 0.038 & 0.040 & 0.039 & 0.040 & 0.039 & 0.040 & 0.039 & 0.040 & 0.039 & 0.040 \\
\hline 6 & 0.038 & 0.042 & 0.038 & 0.042 & 0.038 & 0.042 & 0.038 & 0.042 & 0.040 & 0.040 & 0.040 & 0.040 & 0.040 & 0.040 & 0.040 & 0.040 \\
\hline 8 & 0.040 & 0.042 & 0.040 & 0.042 & 0.040 & 0.042 & 0.040 & 0.042 & 0.042 & 0.043 & 0.042 & 0.043 & 0.042 & 0.043 & 0.042 & 0.043 \\
\hline 10 & 0.041 & 0.044 & 0.041 & 0.044 & 0.041 & 0.044 & 0.042 & 0.044 & 0.044 & 0.044 & 0.044 & 0.044 & 0.044 & 0.044 & 0.044 & 0.044 \\
\hline 15 & 0.046 & 0.046 & 0.046 & 0.046 & 0.046 & 0.046 & 0.046 & 0.046 & 0.049 & 0.050 & 0.049 & 0.050 & 0.049 & 0.050 & 0.049 & 0.051 \\
\hline
\end{tabular}




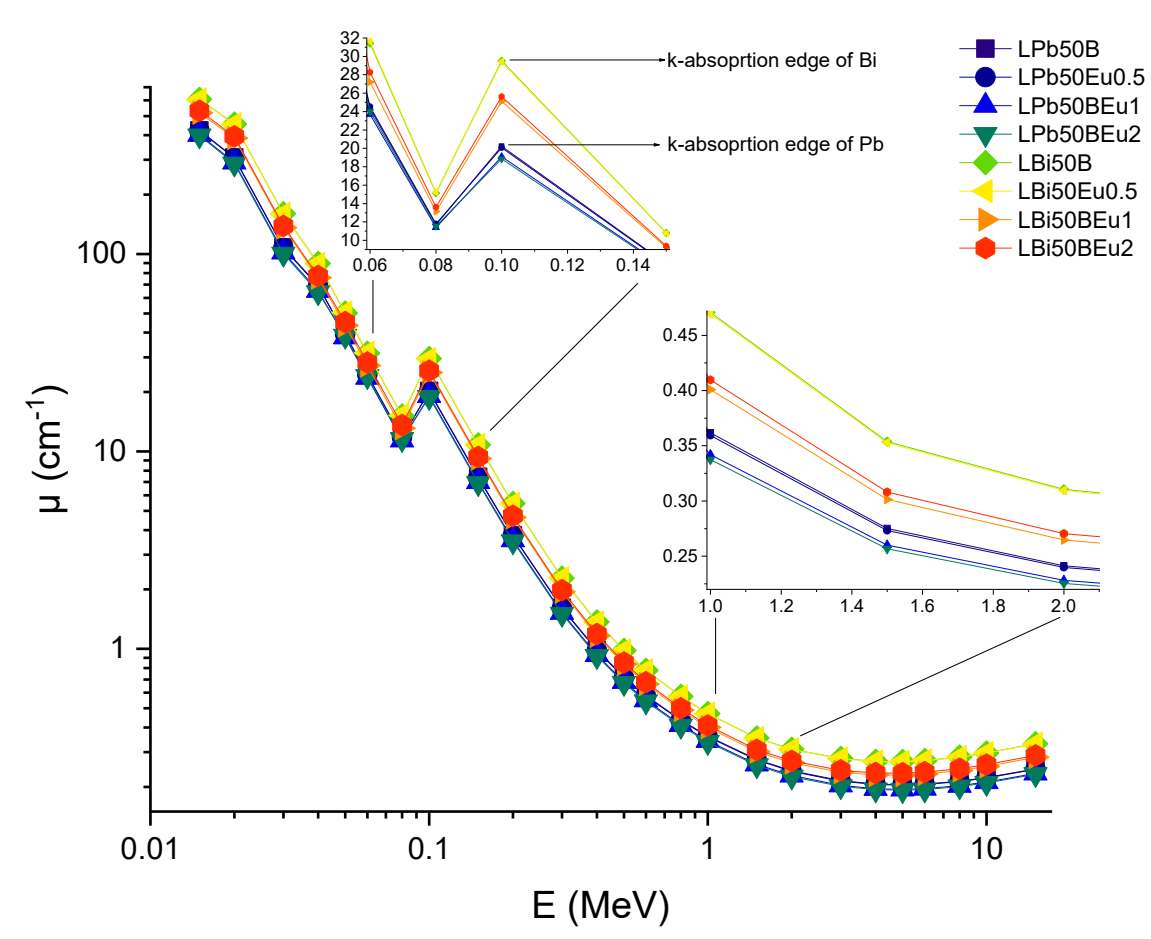

Figure 2. Variation of linear attenuation coefficients $(\mu)$ against photon energy for all glasses.
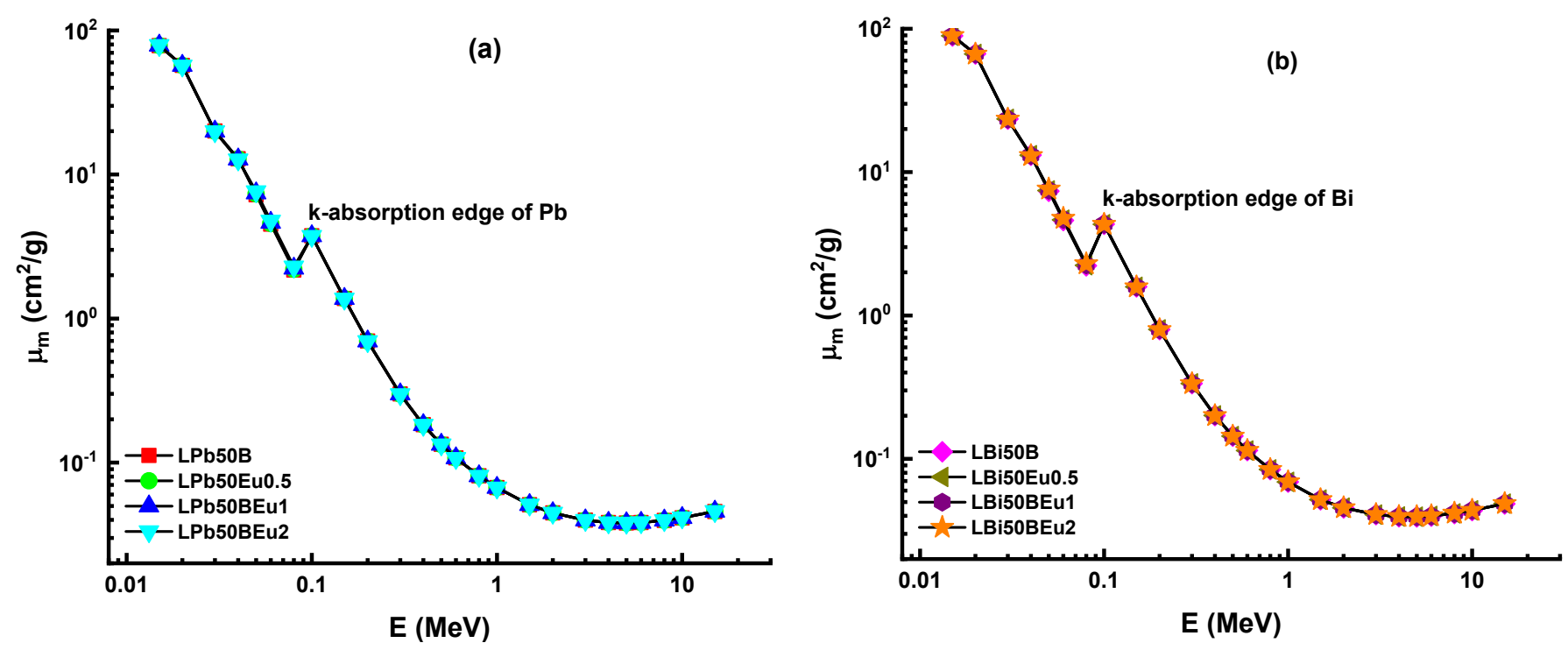

Figure 3. Variation of mass attenuation coefficient $\left(\mu_{m}\right)$ against photon energy for (a) LPb50BEu and (b) LBi50BEu glasses.

Half-value layers $\left(\mathrm{T}_{1 / 2}\right)$ of the LPb50BEu and LBi50BEu glasses are almost zero in the $0.015-0.1 \mathrm{MeV}$ range. After $0.1 \mathrm{MeV}$, secondary scattering enhances with the effect of CS, while the $T_{1 / 2}$ values increase quickly. Beyond $3 \mathrm{MeV}$, the $T_{1 / 2}$ values reduce with the annihilation of photons in the PP process. The densities of LPb50BEu and LBi50BEu glasses are reduced in the range of $5.39-5.04 \mathrm{~g} / \mathrm{cm}^{3}$ and $6.81-5.94 \mathrm{~g} / \mathrm{cm}^{3}$ with the addition of $\mathrm{Eu}_{2} \mathrm{O}_{3}$. Therefore, it is seen that the $\mathrm{T}_{1 / 2}$ values increase with the insertion of $\mathrm{Eu}_{2} \mathrm{O}_{3}$. The maximum $\mathrm{T}_{1 / 2}$ values for $\mathrm{LPb50BEu}$ and LBi50BEu glasses were obtained as $3.60 \mathrm{~cm}$ and $2.95 \mathrm{~cm}$, respectively. These results are quite satisfactory for a good shield material for gamma rays. Moreover, the mean free path values $(\lambda)$ of proposed glasses in comparison with some commercial SCHOTT [17] glasses, RS-253-G18, RS-360, RS-520, and concrete types, barite, ferrite, chromite [18], are given in Figure 4. 

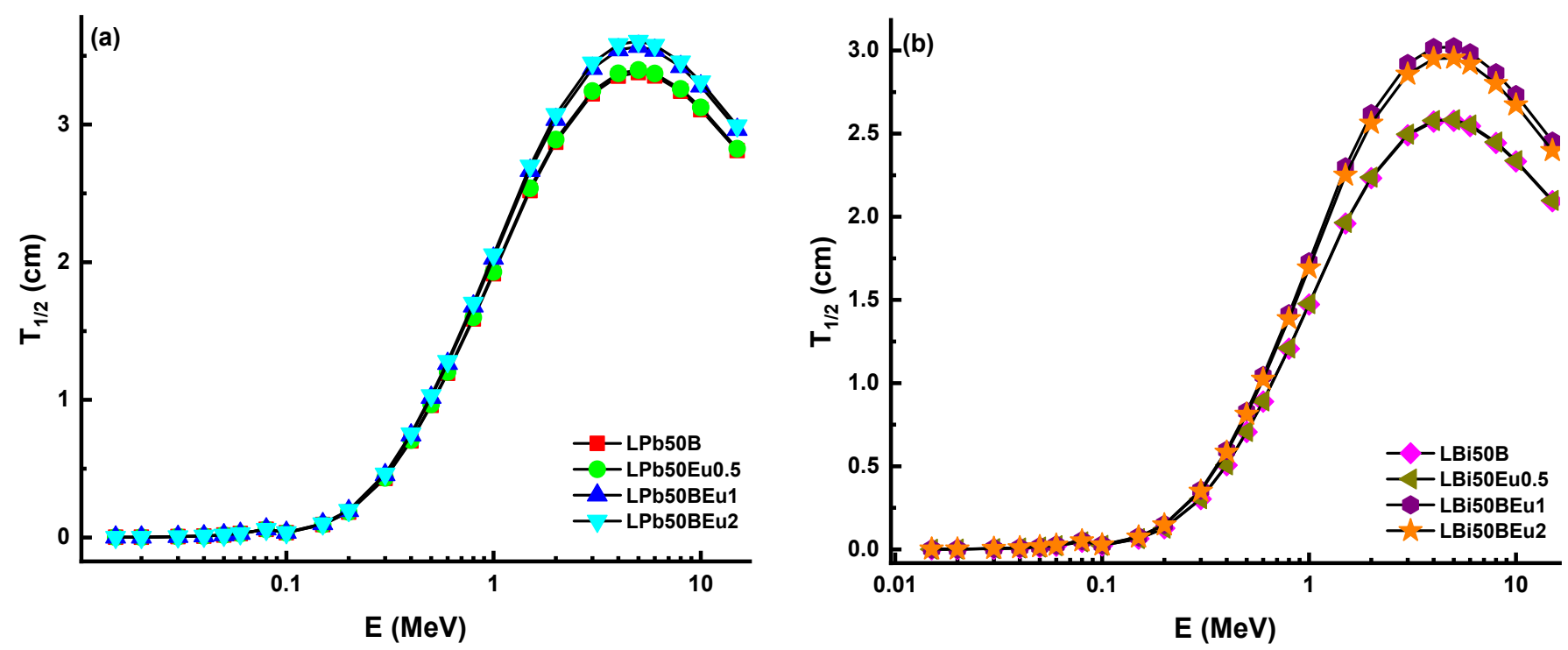

Figure 4. Variation of half-value layer $\left(\mathrm{T}_{1 / 2}\right)$ against photon energy for (a) LPb50BEu and (b) LBi50BEu glasses.

The $\lambda$ values of $\mathrm{LPb50BEu}$ and LBi50BEu glasses are thinner than other shielding materials. The LBi50BEu2 glass had the smallest $\lambda$ values, while the RS-213-G18 glass presented the largest MFP values, as seen in Figure 5. In order to express a composite material with a single atomic number, an effective atomic number $\left(Z_{e f f}\right)$ is needed, which shows the shielding capacity of the shielding material well [19]. Figure 6 presents the change of $Z_{\text {eff }}$ values of $\mathrm{L}(\mathrm{Bi} / \mathrm{Pb}) 50 \mathrm{BEu} 2$ glasses versus photon energy. For LPb50BEu and LBi50BEu glasses, the $Z_{\text {eff }}$ takes values in the range of 76.72-23.15, 75.73-23.84, and 79.64-27.71, 79.38-28.18, respectively. The largest values of $Z_{\text {eff }}$ are at low energies below $0.1 \mathrm{MeV}$. A few sudden peaks occur on the absorption edge of $\mathrm{K}$ and $\mathrm{L}$ shells of $\mathrm{Pb}$ (L:15.86 keV, K:88.00 keV) and Bi (L:16.38 keV, K: $90.52 \mathrm{keV})$, and K shell of La (38.92 keV) by the effect of PEA. Between $0.1-1 \mathrm{MeV}$, the $Z_{\text {eff }}$ values rapidly decrease and, beyond $1 \mathrm{MeV}$, the $Z_{\text {eff }}$ values increased due to the $Z^{2}$-dependent change of the PP cross section. While the addition of $\mathrm{Eu}_{2} \mathrm{O}_{3}$ in the high energy region increased the $Z_{\text {eff }}$ values of the glasses, the $Z_{\text {eff }}$ values declined at medium and low energy levels. It is noted from Figure 6 that the $Z_{\text {eff }}$ values of LBi50BEu glasses prepared with $\mathrm{Bi}_{2} \mathrm{O}_{3}$ are higher than LPb50BEu glasses. Perfect geometry is not possible in real radiation applications. For this reason, the correction factor B (build-up factor) is needed to account for scattering in the material and in the air in the Lambert-Beer law [20]. Energy absorption and exposure build-up factors (EABF and $\mathrm{EBF})$ for $\mathrm{L}(\mathrm{Pb} / \mathrm{Bi}) 50 \mathrm{BEu}$ glasses were generated using Phy-X/PSD software in photon energies of $0.015-15 \mathrm{MeV}$ for several $\lambda$ values.

Figures 7 and 8 visualise the trend of change of the EBF and EABF values of the glasses versus the photon energy and Tables 3-10 presented G-P fitting coefficients, respectively. In the low energy range $(0.015-0.1 \mathrm{MeV})$, it is seen that there are very sharp peaks around $0.02 \mathrm{MeV}, 0.04 \mathrm{MeV}$, and $0.1 \mathrm{MeV}$, which are the $\mathrm{L}$ and $\mathrm{K}$ absorption edges of the $\mathrm{Pb}$ and $\mathrm{Bi}$ elements and the $\mathrm{K}$ shell absorption edge of La. The high $\mathrm{Z}$ values of the relevant elements increase the possibility of PEA interaction and cause the photons to become built up. The EBF and EABF values of LBi50BEu glasses are considerably lower than those of LPb50BEu glasses at lower energies. Since the $Z_{\text {eff }}$ values of the glasses are very large, the $\mathrm{EBF}$ and EABF values for all glasses possess the smallest values (nearly zero) in the CS process proportional to $\mathrm{Z}$. In the range of $1-15 \mathrm{MeV}$, since the PP interaction cross-section is dependent on $Z^{2}$, especially when the depth of penetration increases, photon build-up enhances with secondary scatterings. As a result, the EBF and EABF values for all glasses start to boost again at high energies. It is clear from Figures 7 and 8 that the EBFs of the glasses are higher than the EABFs. 


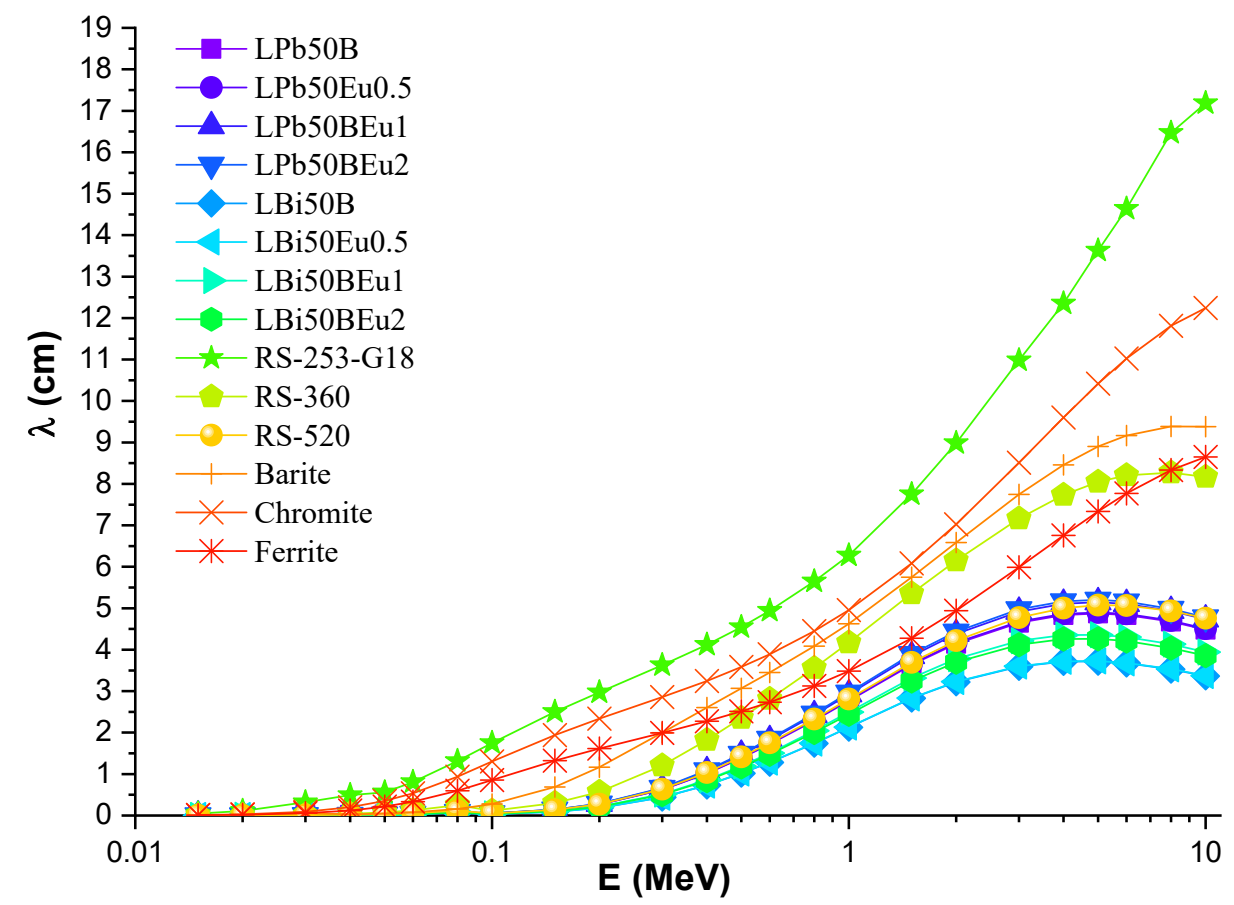

Figure 5. Variation of mean free path $(\lambda)$ against photon energy for LPb50BEu and LBi50BEu glasses, and some commercial shielding materials.
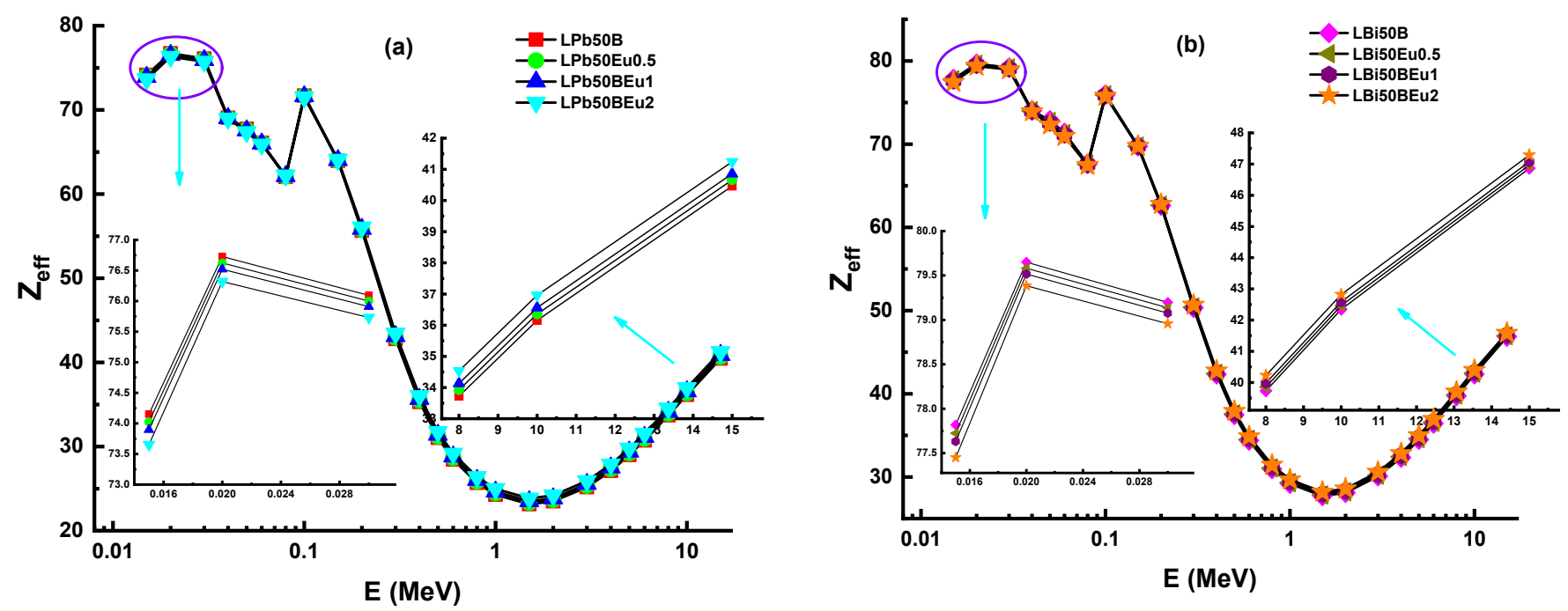

Figure 6. Variation of effective atomic number $\left(Z_{\text {eff }}\right)$ against photon energy for (a) LPb50BEu and (b) LBi50BEu glasses.

When all gamma-shielding parameters are evaluated together, the LBi50BEu glasses show a superior performance compared to LPb50BEu glasses in reducing photons. Besides, the protection capability of $\mathrm{L}(\mathrm{Pb} / \mathrm{Bi}) 50 \mathrm{BEu}$ glasses against uncharged (fast neutrons) and charged particles (alpha and protons) was also evaluated. For this purpose, the macroscopic removal cross-section $\left(\Sigma_{R}\right)$ of glasses for fast neutrons was calculated firstly. 


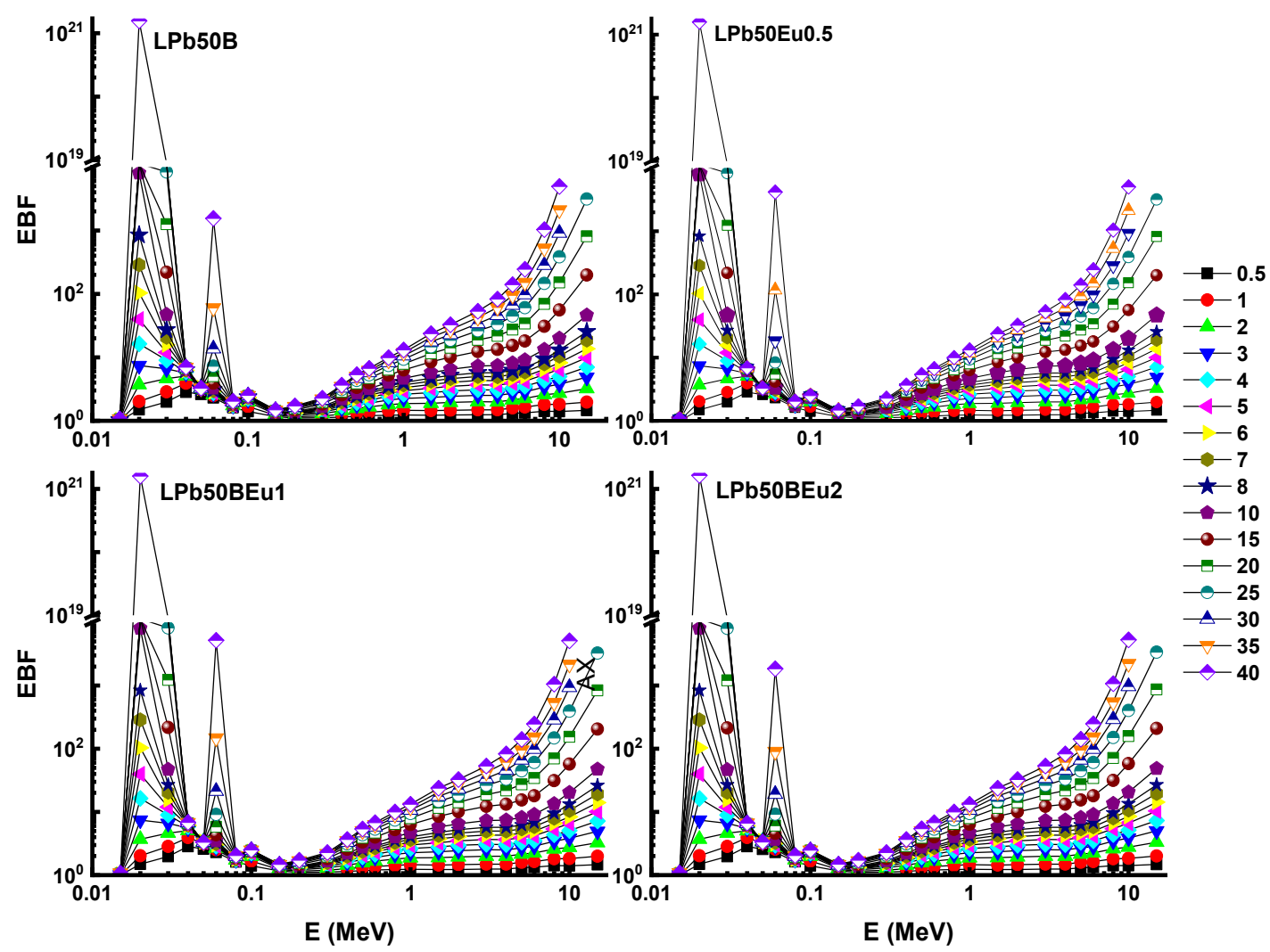

(a)
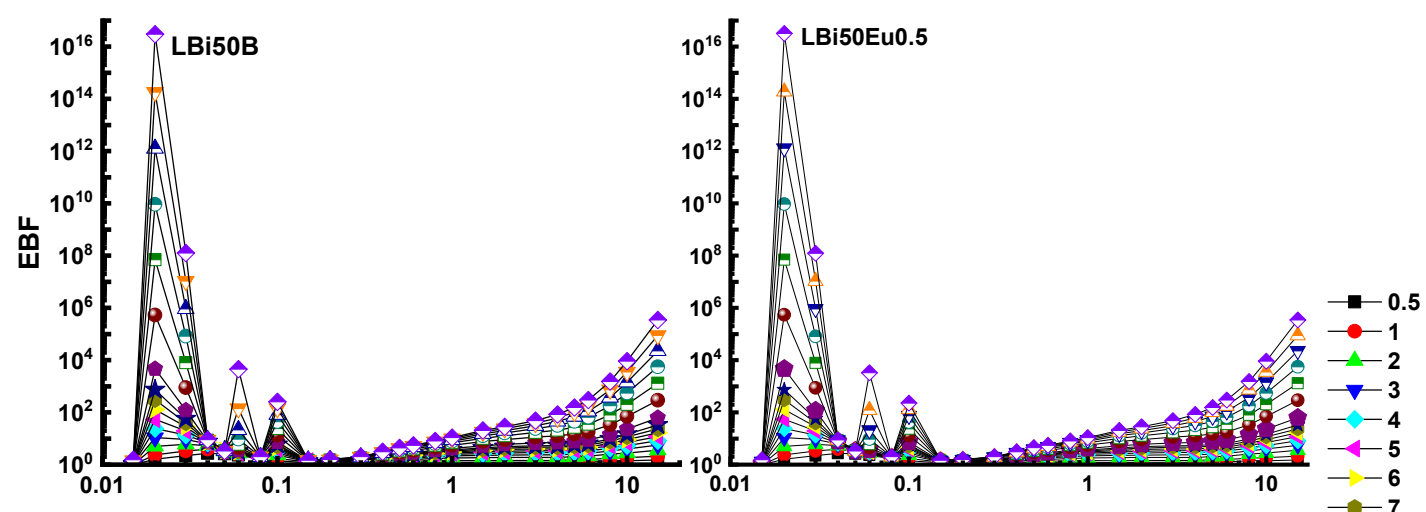

$-1$

$-1-2$

$-3$
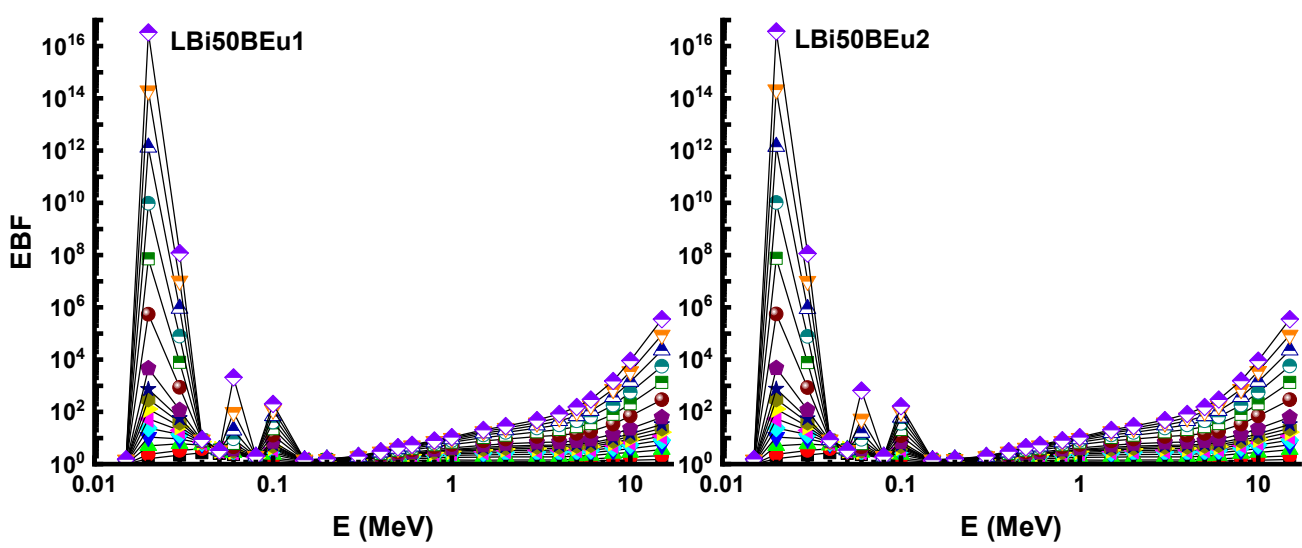

(b)

Figure 7. Variation of exposure build-up factor (EBF) against photon energy for (a) LPb50BEu and (b) LBi50BEu glasses. 


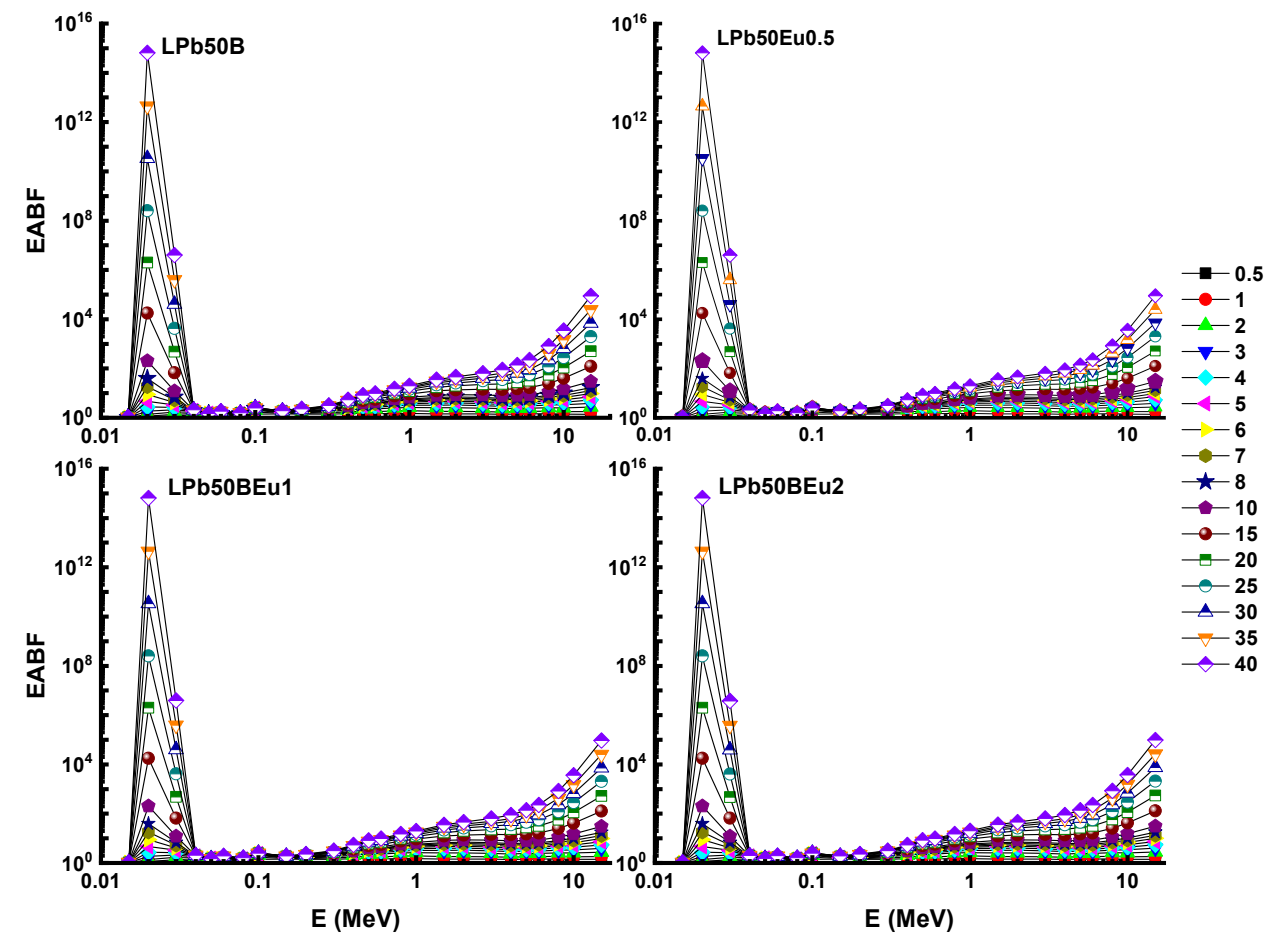

(a)
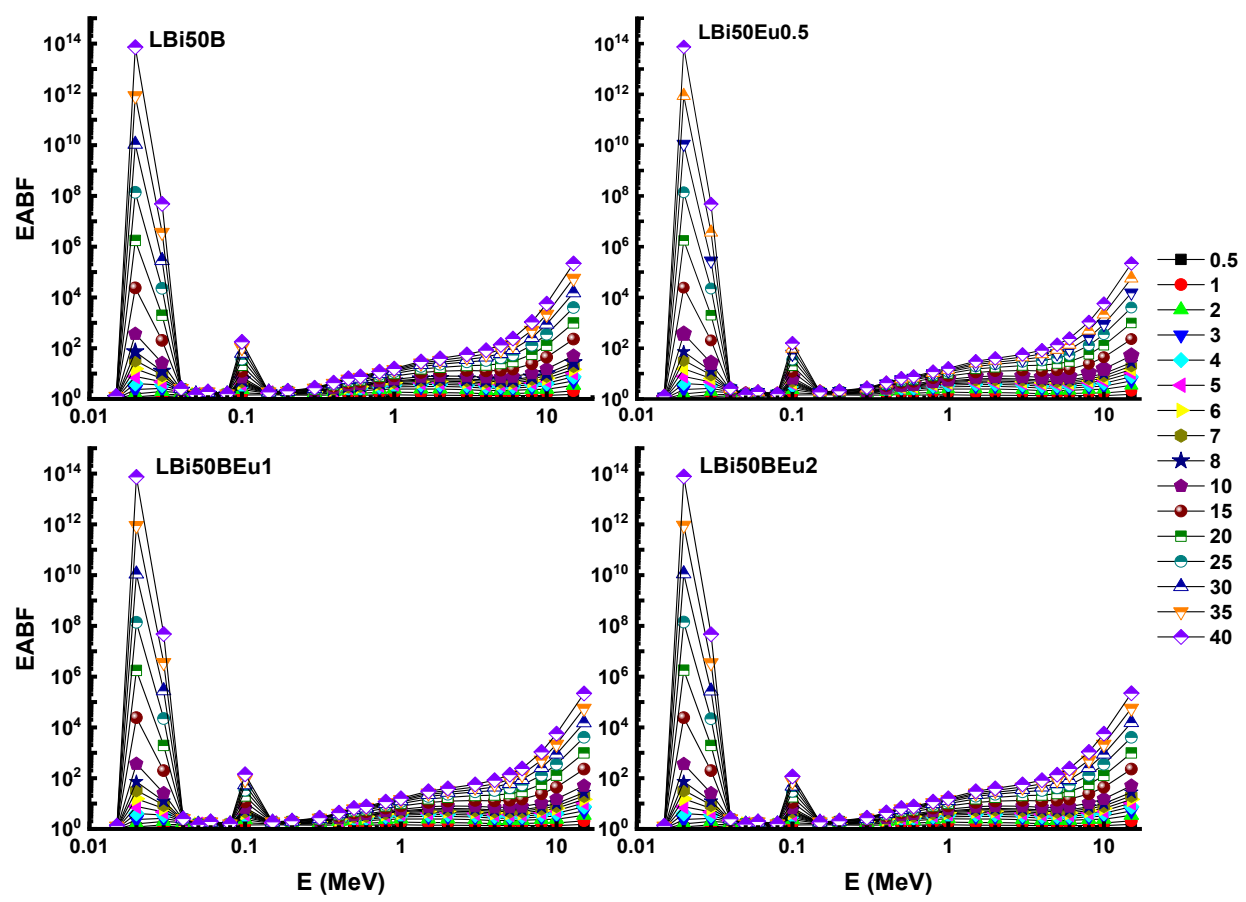

(b)

Figure 8. Variation of energy absorption build-up factor (EABF) against photon energy for (a) LPb50BEu and (b) LBi50BEu glasses. 
Table 3. (EBF and EABF) G-P fitting coefficients (b, c, a, Xk and d) of LPb50B glass sample.

\begin{tabular}{|c|c|c|c|c|c|c|c|c|c|c|c|}
\hline \multirow{2}{*}{$\begin{array}{l}\text { Energy } \\
(\mathrm{MeV})\end{array}$} & \multirow{2}{*}{$\mathrm{Z}_{\mathrm{eq}}$} & \multicolumn{5}{|c|}{ G-P Fitting Parameters for EBF } & \multicolumn{5}{|c|}{ G-P Fitting Parameters for EABF } \\
\hline & & a & $\mathbf{b}$ & c & d & $X_{k}$ & a & $\mathbf{b}$ & $\mathrm{c}$ & d & $X_{k}$ \\
\hline 0.015 & 74.15 & 0.205 & 1.003 & 1.713 & 0.181 & 11.440 & -0.210 & 1.003 & 1.716 & 0.186 & 11.783 \\
\hline 0.020 & 76.73 & 0.278 & 2.024 & 1.365 & -0.373 & 12.434 & 0.165 & 1.151 & 1.421 & -0.181 & 16.239 \\
\hline 0.030 & 76.09 & 0.138 & 2.850 & 0.870 & -0.167 & 26.054 & 0.149 & 1.364 & 0.879 & -0.137 & 22.948 \\
\hline 0.040 & 69.07 & 0.089 & 3.918 & 0.379 & -0.038 & 23.557 & 0.106 & 1.500 & 0.380 & -0.044 & 22.592 \\
\hline 0.050 & 67.75 & -0.246 & 3.154 & 0.092 & 0.021 & 12.536 & -0.102 & 1.413 & 0.104 & 0.079 & 9.298 \\
\hline 0.060 & 66.10 & 0.917 & 2.496 & 0.042 & -0.133 & 15.462 & 0.655 & 1.367 & 0.061 & -0.151 & 15.939 \\
\hline 0.080 & 62.03 & 0.777 & 1.695 & 0.029 & -0.232 & 14.645 & 0.610 & 1.322 & 0.070 & -0.228 & 14.087 \\
\hline 0.100 & 71.70 & 0.052 & 1.669 & 0.463 & -0.009 & 18.106 & 0.055 & 1.695 & 0.449 & -0.013 & 17.643 \\
\hline 0.150 & 63.95 & 0.415 & 1.225 & 0.147 & -0.175 & 14.453 & 0.502 & 1.528 & 0.083 & -0.170 & 18.968 \\
\hline 0.200 & 55.65 & 0.294 & 1.157 & 0.312 & -0.163 & 13.906 & 0.565 & 1.505 & 0.106 & -0.286 & 13.864 \\
\hline 0.300 & 42.79 & 0.159 & 1.194 & 0.509 & -0.075 & 13.692 & 0.366 & 1.596 & 0.235 & -0.203 & 13.337 \\
\hline 0.400 & 35.31 & 0.115 & 1.263 & 0.624 & -0.061 & 14.170 & 0.276 & 1.746 & 0.355 & -0.175 & 13.734 \\
\hline 0.500 & 31.03 & 0.091 & 1.324 & 0.694 & -0.051 & 14.136 & 0.220 & 1.864 & 0.447 & -0.145 & 13.774 \\
\hline 0.600 & 28.46 & 0.074 & 1.368 & 0.745 & -0.041 & 13.708 & 0.158 & 1.791 & 0.559 & -0.103 & 13.603 \\
\hline 0.800 & 25.68 & 0.052 & 1.430 & 0.817 & -0.032 & 13.705 & 0.120 & 1.896 & 0.650 & -0.083 & 13.585 \\
\hline 1.000 & 24.29 & 0.037 & 1.460 & 0.873 & -0.027 & 13.388 & 0.098 & 1.924 & 0.713 & -0.074 & 13.525 \\
\hline 1.500 & 23.15 & 0.010 & 1.445 & 0.992 & -0.020 & 14.204 & 0.055 & 1.823 & 0.858 & -0.055 & 13.794 \\
\hline 2.000 & 23.49 & 0.004 & 1.465 & 1.028 & -0.020 & 13.264 & 0.062 & 1.829 & 0.855 & -0.069 & 13.402 \\
\hline 3.000 & 25.18 & 0.018 & 1.491 & 1.014 & -0.044 & 13.268 & 0.093 & 1.792 & 0.801 & -0.111 & 13.528 \\
\hline 4.000 & 27.12 & 0.035 & 1.494 & 0.979 & -0.059 & 13.740 & 0.107 & 1.722 & 0.778 & -0.125 & 13.860 \\
\hline 5.000 & 29.00 & 0.068 & 1.594 & 0.894 & -0.088 & 13.964 & 0.143 & 1.813 & 0.706 & -0.157 & 14.119 \\
\hline 6.000 & 30.73 & 0.076 & 1.646 & 0.886 & -0.092 & 14.188 & 0.144 & 1.813 & 0.712 & -0.157 & 14.272 \\
\hline 8.000 & 33.72 & 0.073 & 1.801 & 0.927 & -0.092 & 14.177 & 0.127 & 1.845 & 0.782 & -0.143 & 14.289 \\
\hline 10.000 & 36.15 & 0.038 & 1.816 & 1.081 & -0.061 & 14.089 & 0.087 & 1.772 & 0.926 & -0.109 & 14.116 \\
\hline 15.000 & 40.46 & 0.014 & 1.972 & 1.277 & -0.046 & 13.761 & 0.053 & 1.784 & 1.127 & -0.086 & 13.883 \\
\hline
\end{tabular}

Table 4. (EBF and EABF) G-P fitting coefficients (b, c, a, Xk and d) of LPb50Eu0.5 glass sample.

\begin{tabular}{|c|c|c|c|c|c|c|c|c|c|c|c|}
\hline \multirow{2}{*}{$\begin{array}{l}\text { Energy } \\
(\mathrm{MeV})\end{array}$} & \multirow{2}{*}{$\mathrm{Z}_{\mathrm{eq}}$} & \multicolumn{5}{|c|}{ G-P Fitting Parameters for EBF } & \multicolumn{5}{|c|}{ G-P Fitting Parameters for EABF } \\
\hline & & $\mathbf{a}$ & $\mathbf{b}$ & c & d & $X_{k}$ & $\mathbf{a}$ & $\mathbf{b}$ & c & d & $X_{k}$ \\
\hline 0.015 & 74.02 & 0.203 & 1.003 & 1.707 & 0.180 & 11.445 & 0.208 & 1.003 & 1.710 & 0.185 & 11.794 \\
\hline 0.020 & 76.62 & 0.278 & 2.024 & 1.365 & -0.373 & 12.433 & 0.165 & 1.151 & 1.420 & -0.181 & 16.237 \\
\hline 0.030 & 76.00 & 0.138 & 2.847 & 0.870 & -0.167 & 26.036 & 0.149 & 1.363 & 0.879 & -0.137 & 22.933 \\
\hline 0.040 & 69.04 & 0.089 & 3.920 & 0.374 & -0.037 & 23.539 & 0.106 & 1.499 & 0.374 & -0.044 & 22.651 \\
\hline 0.050 & 67.64 & -0.227 & 3.166 & 0.106 & 0.012 & 12.690 & -0.089 & 1.422 & 0.118 & 0.068 & 9.564 \\
\hline 0.060 & 66.05 & 0.881 & 2.513 & 0.049 & -0.130 & 15.065 & 0.627 & 1.374 & 0.069 & -0.143 & 16.138 \\
\hline 0.080 & 62.08 & 0.779 & 1.700 & 0.029 & -0.229 & 14.677 & 0.615 & 1.325 & 0.069 & -0.228 & 14.093 \\
\hline 0.100 & 71.66 & 0.052 & 1.669 & 0.462 & -0.009 & 18.112 & 0.055 & 1.695 & 0.448 & -0.013 & 17.647 \\
\hline 0.150 & 63.99 & 0.415 & 1.224 & 0.147 & -0.176 & 14.450 & 0.503 & 1.528 & 0.083 & -0.171 & 18.939 \\
\hline 0.200 & 55.75 & 0.293 & 1.157 & 0.312 & -0.163 & 13.908 & 0.565 & 1.505 & 0.106 & -0.286 & 13.863 \\
\hline 0.300 & 42.95 & 0.158 & 1.194 & 0.509 & -0.075 & 13.693 & 0.365 & 1.597 & 0.235 & -0.203 & 13.337 \\
\hline 0.400 & 35.48 & 0.115 & 1.264 & 0.624 & -0.061 & 14.171 & 0.276 & 1.747 & 0.355 & -0.175 & 13.734 \\
\hline 0.500 & 31.21 & 0.091 & 1.325 & 0.695 & -0.051 & 14.136 & 0.220 & 1.865 & 0.447 & -0.145 & 13.775 \\
\hline 0.600 & 28.64 & 0.073 & 1.369 & 0.745 & -0.041 & 13.708 & 0.157 & 1.792 & 0.560 & -0.103 & 13.604 \\
\hline 0.800 & 25.86 & 0.052 & 1.431 & 0.818 & -0.032 & 13.704 & 0.120 & 1.897 & 0.650 & -0.083 & 13.586 \\
\hline 1.000 & 24.46 & 0.037 & 1.461 & 0.873 & -0.027 & 13.388 & 0.098 & 1.925 & 0.714 & -0.074 & 13.525 \\
\hline 1.500 & 23.33 & 0.010 & 1.446 & 0.992 & -0.020 & 14.203 & 0.055 & 1.824 & 0.858 & -0.055 & 13.793 \\
\hline 2.000 & 23.67 & 0.004 & 1.465 & 1.028 & -0.020 & 13.263 & 0.062 & 1.830 & 0.855 & -0.069 & 13.402 \\
\hline 3.000 & 25.37 & 0.018 & 1.491 & 1.014 & -0.044 & 13.267 & 0.093 & 1.792 & 0.801 & -0.111 & 13.528 \\
\hline 4.000 & 27.31 & 0.035 & 1.494 & 0.979 & -0.059 & 13.740 & 0.107 & 1.721 & 0.778 & -0.125 & 13.860 \\
\hline 5.000 & 29.20 & 0.068 & 1.593 & 0.894 & -0.088 & 13.965 & 0.143 & 1.811 & 0.706 & -0.157 & 14.119 \\
\hline 6.000 & 30.93 & 0.076 & 1.645 & 0.886 & -0.092 & 14.188 & 0.144 & 1.811 & 0.712 & -0.157 & 14.272 \\
\hline 8.000 & 33.93 & 0.073 & 1.805 & 0.927 & -0.092 & 14.177 & 0.127 & 1.850 & 0.781 & -0.143 & 14.288 \\
\hline 10.000 & 36.36 & 0.038 & 1.822 & 1.082 & -0.061 & 14.088 & 0.087 & 1.779 & 0.926 & -0.109 & 14.113 \\
\hline 15.000 & 40.66 & 0.014 & 1.981 & 1.279 & -0.045 & 13.758 & 0.053 & 1.793 & 1.128 & -0.086 & 13.878 \\
\hline
\end{tabular}


Table 5. (EBF and EABF) G-P fitting coefficients (b, c, a, Xk and d) of LPb50Eu1 glass sample.

\begin{tabular}{|c|c|c|c|c|c|c|c|c|c|c|c|}
\hline \multirow{2}{*}{$\begin{array}{l}\text { Energy } \\
(\mathrm{MeV})\end{array}$} & \multirow{2}{*}{$\mathrm{Z}_{\mathrm{eq}}$} & \multicolumn{5}{|c|}{ G-P Fitting Parameters for EBF } & \multicolumn{5}{|c|}{ G-P Fitting Parameters for EABF } \\
\hline & & a & $\mathbf{b}$ & c & d & $X_{k}$ & a & $\mathbf{b}$ & c & d & $X_{k}$ \\
\hline 0.015 & 73.90 & 0.201 & 1.003 & 1.701 & 0.178 & 11.450 & 0.206 & 1.003 & 1.704 & 0.183 & 11.806 \\
\hline 0.020 & 76.52 & 0.278 & 2.023 & 1.364 & -0.374 & 12.432 & 0.165 & 1.151 & 1.420 & -0.181 & 16.235 \\
\hline 0.030 & 75.91 & 0.138 & 2.845 & 0.869 & -0.167 & 26.018 & 0.149 & 1.363 & 0.878 & -0.137 & 22.919 \\
\hline 0.040 & 69.02 & 0.088 & 3.922 & 0.368 & -0.037 & 23.522 & 0.106 & 1.498 & 0.368 & -0.044 & 22.710 \\
\hline 0.050 & 67.55 & -0.208 & 3.178 & 0.121 & 0.002 & 12.842 & -0.075 & 1.430 & 0.132 & 0.056 & 9.827 \\
\hline 0.060 & 66.00 & 0.847 & 2.530 & 0.056 & -0.127 & 14.682 & 0.600 & 1.382 & 0.076 & -0.136 & 16.329 \\
\hline 0.080 & 62.13 & 0.780 & 1.704 & 0.028 & -0.226 & 14.710 & 0.620 & 1.327 & 0.067 & -0.228 & 14.099 \\
\hline 0.100 & 71.61 & 0.052 & 1.669 & 0.461 & -0.009 & 18.118 & 0.054 & 1.695 & 0.447 & -0.013 & 17.650 \\
\hline 0.150 & 64.03 & 0.416 & 1.224 & 0.147 & -0.176 & 14.446 & 0.504 & 1.528 & 0.082 & -0.172 & 18.911 \\
\hline 0.200 & 55.85 & 0.293 & 1.157 & 0.313 & -0.162 & 13.910 & 0.564 & 1.504 & 0.106 & -0.286 & 13.863 \\
\hline 0.300 & 43.11 & 0.158 & 1.194 & 0.509 & -0.075 & 13.693 & 0.365 & 1.597 & 0.235 & -0.203 & 13.337 \\
\hline 0.400 & 35.66 & 0.115 & 1.264 & 0.624 & -0.061 & 14.171 & 0.275 & 1.747 & 0.355 & -0.175 & 13.734 \\
\hline 0.500 & 31.39 & 0.091 & 1.325 & 0.695 & -0.050 & 14.136 & 0.220 & 1.866 & 0.448 & -0.144 & 13.775 \\
\hline 0.600 & 28.81 & 0.073 & 1.369 & 0.745 & -0.041 & 13.708 & 0.157 & 1.794 & 0.560 & -0.103 & 13.604 \\
\hline 0.800 & 26.03 & 0.052 & 1.431 & 0.818 & -0.032 & 13.704 & 0.120 & 1.898 & 0.651 & -0.082 & 13.586 \\
\hline 1.000 & 24.63 & 0.037 & 1.461 & 0.874 & -0.027 & 13.389 & 0.098 & 1.925 & 0.714 & -0.074 & 13.525 \\
\hline 1.500 & 23.50 & 0.010 & 1.446 & 0.993 & -0.020 & 14.202 & 0.055 & 1.824 & 0.858 & -0.055 & 13.792 \\
\hline 2.000 & 23.84 & 0.004 & 1.465 & 1.028 & -0.020 & 13.263 & 0.062 & 1.830 & 0.855 & -0.069 & 13.402 \\
\hline 3.000 & 25.55 & 0.018 & 1.491 & 1.014 & -0.044 & 13.267 & 0.093 & 1.792 & 0.801 & -0.111 & 13.528 \\
\hline 4.000 & 27.50 & 0.035 & 1.493 & 0.979 & -0.059 & 13.740 & 0.107 & 1.720 & 0.778 & -0.125 & 13.860 \\
\hline 5.000 & 29.39 & 0.068 & 1.592 & 0.895 & -0.088 & 13.965 & 0.143 & 1.809 & 0.707 & -0.157 & 14.120 \\
\hline 6.000 & 31.13 & 0.075 & 1.643 & 0.886 & -0.092 & 14.188 & 0.144 & 1.808 & 0.712 & -0.157 & 14.272 \\
\hline 8.000 & 34.13 & 0.073 & 1.809 & 0.927 & -0.091 & 14.178 & 0.127 & 1.856 & 0.781 & -0.143 & 14.287 \\
\hline 10.000 & 36.56 & 0.038 & 1.828 & 1.083 & -0.061 & 14.086 & 0.087 & 1.785 & 0.927 & -0.109 & 14.110 \\
\hline 15.000 & 40.86 & 0.014 & 1.990 & 1.281 & -0.045 & 13.754 & 0.053 & 1.802 & 1.129 & -0.086 & 13.873 \\
\hline
\end{tabular}

Table 6. (EBF and EABF) G-P fitting coefficients (b, c, a, Xk and d) of LPb50Eu2 glass sample.

\begin{tabular}{|c|c|c|c|c|c|c|c|c|c|c|c|}
\hline \multirow{2}{*}{$\begin{array}{l}\text { Energy } \\
(\mathrm{MeV})\end{array}$} & \multirow{2}{*}{$\mathrm{Z}_{\mathrm{eq}}$} & \multicolumn{5}{|c|}{ G-P Fitting Parameters for EBF } & \multicolumn{5}{|c|}{ G-P Fitting Parameters for EABF } \\
\hline & & $\mathbf{a}$ & $\mathbf{b}$ & c & d & $X_{k}$ & $\mathbf{a}$ & $\mathbf{b}$ & c & d & $X_{k}$ \\
\hline 0.015 & 73.65 & 0.197 & 1.003 & 1.690 & 0.176 & 11.460 & 0.202 & 1.003 & 1.693 & 0.181 & 11.828 \\
\hline 0.020 & 76.32 & 0.279 & 2.022 & 1.363 & -0.374 & 12.431 & 0.166 & 1.151 & 1.419 & -0.181 & 16.232 \\
\hline 0.030 & 75.73 & 0.138 & 2.841 & 0.868 & -0.167 & 25.984 & 0.149 & 1.362 & 0.877 & -0.137 & 22.890 \\
\hline 0.040 & 68.98 & 0.088 & 3.926 & 0.358 & -0.036 & 23.488 & 0.106 & 1.496 & 0.358 & -0.044 & 22.825 \\
\hline 0.050 & 67.37 & -0.173 & 3.200 & 0.147 & -0.015 & 13.130 & -0.049 & 1.445 & 0.158 & 0.035 & 10.325 \\
\hline 0.060 & 65.90 & 0.781 & 2.561 & 0.070 & -0.122 & 13.950 & 0.549 & 1.396 & 0.090 & -0.121 & 16.695 \\
\hline 0.080 & 62.22 & 0.783 & 1.713 & 0.027 & -0.219 & 14.771 & 0.630 & 1.333 & 0.064 & -0.228 & 14.111 \\
\hline 0.100 & 71.52 & 0.051 & 1.668 & 0.459 & -0.008 & 18.130 & 0.054 & 1.694 & 0.445 & -0.012 & 17.657 \\
\hline 0.150 & 64.09 & 0.416 & 1.224 & 0.147 & -0.177 & 14.439 & 0.506 & 1.527 & 0.082 & -0.174 & 18.855 \\
\hline 0.200 & 56.05 & 0.292 & 1.157 & 0.314 & -0.162 & 13.913 & 0.564 & 1.504 & 0.107 & -0.285 & 13.862 \\
\hline 0.300 & 43.44 & 0.158 & 1.195 & 0.509 & -0.075 & 13.695 & 0.364 & 1.598 & 0.236 & -0.203 & 13.338 \\
\hline 0.400 & 36.01 & 0.115 & 1.265 & 0.625 & -0.061 & 14.172 & 0.275 & 1.749 & 0.356 & -0.175 & 13.735 \\
\hline 0.500 & 31.75 & 0.091 & 1.326 & 0.696 & -0.050 & 14.137 & 0.219 & 1.868 & 0.448 & -0.144 & 13.776 \\
\hline 0.600 & 29.17 & 0.073 & 1.370 & 0.746 & -0.041 & 13.709 & 0.157 & 1.796 & 0.561 & -0.102 & 13.605 \\
\hline 0.800 & 26.38 & 0.051 & 1.432 & 0.819 & -0.032 & 13.704 & 0.120 & 1.900 & 0.651 & -0.082 & 13.586 \\
\hline 1.000 & 24.98 & 0.037 & 1.462 & 0.874 & -0.027 & 13.391 & 0.098 & 1.927 & 0.715 & -0.074 & 13.524 \\
\hline 1.500 & 23.84 & 0.010 & 1.447 & 0.993 & -0.019 & 14.199 & 0.054 & 1.825 & 0.858 & -0.055 & 13.791 \\
\hline 2.000 & 24.19 & 0.004 & 1.466 & 1.029 & -0.020 & 13.261 & 0.062 & 1.830 & 0.855 & -0.069 & 13.401 \\
\hline 3.000 & 25.92 & 0.018 & 1.491 & 1.014 & -0.044 & 13.266 & 0.093 & 1.791 & 0.801 & -0.111 & 13.528 \\
\hline 4.000 & 27.88 & 0.035 & 1.493 & 0.979 & -0.059 & 13.740 & 0.107 & 1.717 & 0.779 & -0.125 & 13.861 \\
\hline 5.000 & 29.79 & 0.068 & 1.590 & 0.895 & -0.088 & 13.965 & 0.142 & 1.805 & 0.707 & -0.157 & 14.121 \\
\hline 6.000 & 31.53 & 0.075 & 1.641 & 0.887 & -0.091 & 14.187 & 0.144 & 1.804 & 0.713 & -0.157 & 14.273 \\
\hline 8.000 & 34.54 & 0.073 & 1.818 & 0.928 & -0.091 & 14.178 & 0.127 & 1.867 & 0.780 & -0.143 & 14.285 \\
\hline 10.000 & 36.96 & 0.037 & 1.839 & 1.085 & -0.061 & 14.083 & 0.087 & 1.798 & 0.927 & -0.109 & 14.104 \\
\hline 15.000 & 41.24 & 0.013 & 2.008 & 1.284 & -0.045 & 13.747 & 0.053 & 1.819 & 1.131 & -0.086 & 13.864 \\
\hline
\end{tabular}


Table 7. (EBF and EABF) G-P fitting coefficients (b, c, a, Xk and d) of LBi50B glass sample.

\begin{tabular}{|c|c|c|c|c|c|c|c|c|c|c|c|}
\hline \multirow{2}{*}{$\begin{array}{l}\text { Energy } \\
(\mathrm{MeV})\end{array}$} & \multirow{2}{*}{$\mathrm{Z}_{\mathrm{eq}}$} & \multicolumn{5}{|c|}{ G-P Fitting Parameters for EBF } & \multicolumn{5}{|c|}{ G-P Fitting Parameters for EABF } \\
\hline & & a & $\mathbf{b}$ & c & d & $X_{k}$ & a & $\mathbf{b}$ & c & d & $X_{k}$ \\
\hline 0.015 & 77.82 & 0.109 & 1.004 & 1.411 & 0.116 & 11.705 & 0.118 & 1.004 & 1.416 & 0.125 & 12.362 \\
\hline 0.020 & 79.65 & 0.112 & 2.370 & 1.795 & -0.139 & 12.997 & 0.071 & 1.200 & 1.826 & -0.069 & 17.474 \\
\hline 0.030 & 79.20 & 0.119 & 3.365 & 1.015 & -0.200 & 30.012 & 0.121 & 1.461 & 1.023 & -0.125 & 26.240 \\
\hline 0.040 & 74.03 & 0.089 & 3.880 & 0.472 & -0.048 & 23.861 & 0.104 & 1.517 & 0.477 & -0.042 & 21.572 \\
\hline 0.050 & 72.84 & -0.192 & 3.188 & 0.132 & -0.005 & 12.970 & -0.063 & 1.436 & 0.144 & 0.047 & 10.048 \\
\hline 0.060 & 71.36 & 0.826 & 2.540 & 0.060 & -0.125 & 14.454 & 0.584 & 1.386 & 0.080 & -0.131 & 16.443 \\
\hline 0.080 & 67.62 & 0.780 & 1.706 & 0.028 & -0.224 & 14.721 & 0.622 & 1.328 & 0.067 & -0.228 & 14.101 \\
\hline 0.100 & 75.96 & 0.124 & 1.732 & 0.732 & -0.094 & 16.627 & 0.130 & 1.758 & 0.706 & -0.097 & 16.777 \\
\hline 0.150 & 69.75 & 0.367 & 1.247 & 0.145 & -0.104 & 14.974 & 0.354 & 1.580 & 0.102 & -0.052 & 23.100 \\
\hline 0.200 & 62.62 & 0.340 & 1.155 & 0.256 & -0.192 & 13.709 & 0.623 & 1.519 & 0.078 & -0.300 & 13.939 \\
\hline 0.300 & 50.33 & 0.168 & 1.170 & 0.487 & -0.081 & 13.619 & 0.396 & 1.559 & 0.203 & -0.218 & 13.310 \\
\hline 0.400 & 42.34 & 0.124 & 1.231 & 0.599 & -0.065 & 14.143 & 0.297 & 1.673 & 0.322 & -0.187 & 13.704 \\
\hline 0.500 & 37.45 & 0.099 & 1.288 & 0.669 & -0.053 & 14.136 & 0.238 & 1.783 & 0.412 & -0.155 & 13.734 \\
\hline 0.600 & 34.39 & 0.081 & 1.331 & 0.718 & -0.044 & 13.699 & 0.168 & 1.698 & 0.533 & -0.106 & 13.577 \\
\hline 0.800 & 30.97 & 0.058 & 1.393 & 0.792 & -0.033 & 13.707 & 0.131 & 1.815 & 0.620 & -0.086 & 13.574 \\
\hline 1.000 & 29.20 & 0.043 & 1.426 & 0.847 & -0.028 & 13.385 & 0.108 & 1.854 & 0.684 & -0.077 & 13.527 \\
\hline 1.500 & 27.72 & 0.013 & 1.417 & 0.975 & -0.021 & 14.325 & 0.060 & 1.779 & 0.837 & -0.057 & 13.860 \\
\hline 2.000 & 28.10 & 0.006 & 1.435 & 1.015 & -0.020 & 13.373 & 0.064 & 1.777 & 0.844 & -0.069 & 13.432 \\
\hline 3.000 & 30.09 & 0.016 & 1.446 & 1.019 & -0.041 & 13.341 & 0.090 & 1.721 & 0.807 & -0.107 & 13.535 \\
\hline 4.000 & 32.34 & 0.030 & 1.444 & 0.998 & -0.054 & 13.736 & 0.103 & 1.627 & 0.791 & -0.121 & 13.866 \\
\hline 5.000 & 34.48 & 0.063 & 1.529 & 0.916 & -0.083 & 13.979 & 0.135 & 1.663 & 0.728 & -0.150 & 14.150 \\
\hline 6.000 & 36.43 & 0.070 & 1.573 & 0.911 & -0.088 & 14.164 & 0.136 & 1.654 & 0.736 & -0.150 & 14.296 \\
\hline 8.000 & 39.73 & 0.068 & 1.763 & 0.955 & -0.087 & 14.145 & 0.122 & 1.727 & 0.803 & -0.139 & 14.280 \\
\hline 10.000 & 42.34 & 0.034 & 1.845 & 1.115 & -0.058 & 14.001 & 0.081 & 1.710 & 0.957 & -0.105 & 14.107 \\
\hline 15.000 & 46.86 & 0.007 & 2.095 & 1.336 & -0.038 & 13.694 & 0.030 & 2.079 & 1.229 & -0.063 & 13.727 \\
\hline
\end{tabular}

Table 8. (EBF and EABF) G-P fitting coefficients (b, c, a, Xk and d) of LBi50Eu0.5 glass sample.

\begin{tabular}{|c|c|c|c|c|c|c|c|c|c|c|c|}
\hline \multirow{2}{*}{$\begin{array}{l}\text { Energy } \\
(\mathrm{MeV})\end{array}$} & \multirow{2}{*}{$\mathrm{Z}_{\mathrm{eq}}$} & \multicolumn{5}{|c|}{ G-P Fitting Parameters for EBF } & \multicolumn{5}{|c|}{ G-P Fitting Parameters for EABF } \\
\hline & & $\mathbf{a}$ & $\mathbf{b}$ & c & d & $X_{k}$ & $\mathbf{a}$ & $\mathbf{b}$ & c & d & $X_{k}$ \\
\hline 0.015 & 77.72 & 0.108 & 1.004 & 1.408 & 0.115 & 11.707 & 0.117 & 1.004 & 1.414 & 0.125 & 12.366 \\
\hline 0.020 & 79.58 & 0.113 & 2.368 & 1.793 & -0.140 & 12.994 & 0.071 & 1.200 & 1.825 & -0.069 & 17.468 \\
\hline 0.030 & 79.14 & 0.119 & 3.362 & 1.014 & -0.200 & 29.987 & 0.121 & 1.461 & 1.022 & -0.125 & 26.220 \\
\hline 0.040 & 74.00 & 0.089 & 3.881 & 0.468 & -0.047 & 23.849 & 0.104 & 1.517 & 0.473 & -0.042 & 21.611 \\
\hline 0.050 & 72.71 & -0.182 & 3.195 & 0.141 & -0.011 & 13.058 & -0.056 & 1.441 & 0.152 & 0.040 & 10.201 \\
\hline 0.060 & 71.25 & 0.806 & 2.549 & 0.064 & -0.124 & 14.230 & 0.569 & 1.390 & 0.084 & -0.127 & 16.555 \\
\hline 0.080 & 67.58 & 0.781 & 1.709 & 0.028 & -0.222 & 14.740 & 0.625 & 1.330 & 0.066 & -0.228 & 14.105 \\
\hline 0.100 & 75.91 & 0.123 & 1.732 & 0.730 & -0.093 & 16.636 & 0.130 & 1.758 & 0.705 & -0.096 & 16.783 \\
\hline 0.150 & 69.75 & 0.367 & 1.247 & 0.145 & -0.105 & 14.970 & 0.355 & 1.579 & 0.102 & -0.052 & 23.068 \\
\hline 0.200 & 62.66 & 0.340 & 1.155 & 0.257 & -0.192 & 13.710 & 0.622 & 1.519 & 0.078 & -0.299 & 13.938 \\
\hline 0.300 & 50.41 & 0.168 & 1.170 & 0.487 & -0.081 & 13.620 & 0.396 & 1.559 & 0.203 & -0.218 & 13.310 \\
\hline 0.400 & 42.44 & 0.124 & 1.232 & 0.599 & -0.065 & 14.142 & 0.297 & 1.674 & 0.323 & -0.186 & 13.705 \\
\hline 0.500 & 37.57 & 0.099 & 1.288 & 0.669 & -0.053 & 14.136 & 0.238 & 1.783 & 0.413 & -0.155 & 13.734 \\
\hline 0.600 & 34.51 & 0.081 & 1.331 & 0.718 & -0.044 & 13.699 & 0.167 & 1.699 & 0.533 & -0.106 & 13.577 \\
\hline 0.800 & 31.08 & 0.058 & 1.393 & 0.792 & -0.033 & 13.708 & 0.131 & 1.816 & 0.620 & -0.086 & 13.574 \\
\hline 1.000 & 29.31 & 0.043 & 1.427 & 0.847 & -0.028 & 13.384 & 0.108 & 1.855 & 0.684 & -0.077 & 13.527 \\
\hline 1.500 & 27.84 & 0.013 & 1.418 & 0.975 & -0.021 & 14.323 & 0.060 & 1.780 & 0.837 & -0.056 & 13.859 \\
\hline 2.000 & 28.22 & 0.006 & 1.436 & 1.015 & -0.020 & 13.372 & 0.064 & 1.777 & 0.845 & -0.069 & 13.432 \\
\hline 3.000 & 30.21 & 0.016 & 1.446 & 1.019 & -0.041 & 13.341 & 0.090 & 1.721 & 0.807 & -0.107 & 13.535 \\
\hline 4.000 & 32.46 & 0.030 & 1.444 & 0.998 & -0.054 & 13.736 & 0.103 & 1.626 & 0.791 & -0.121 & 13.866 \\
\hline 5.000 & 34.61 & 0.063 & 1.529 & 0.916 & -0.083 & 13.979 & 0.135 & 1.663 & 0.728 & -0.150 & 14.150 \\
\hline 6.000 & 36.56 & 0.070 & 1.573 & 0.911 & -0.088 & 14.163 & 0.136 & 1.653 & 0.737 & -0.150 & 14.297 \\
\hline 8.000 & 39.86 & 0.068 & 1.763 & 0.955 & -0.087 & 14.145 & 0.122 & 1.726 & 0.803 & -0.139 & 14.280 \\
\hline 10.000 & 42.46 & 0.034 & 1.844 & 1.115 & -0.058 & 14.001 & 0.081 & 1.709 & 0.957 & -0.105 & 14.107 \\
\hline 15.000 & 46.97 & 0.007 & 2.094 & 1.336 & -0.038 & 13.694 & 0.030 & 2.080 & 1.230 & -0.063 & 13.727 \\
\hline
\end{tabular}


Table 9. (EBF and EABF) G-P fitting coefficients (b, c, a, Xk and d) of LBi50Eu1 glass sample.

\begin{tabular}{|c|c|c|c|c|c|c|c|c|c|c|c|}
\hline \multirow{2}{*}{$\begin{array}{l}\text { Energy } \\
(\mathrm{MeV})\end{array}$} & \multirow{2}{*}{$\mathrm{Z}_{\mathrm{eq}}$} & \multicolumn{5}{|c|}{ G-P Fitting Parameters for EBF } & \multicolumn{5}{|c|}{ G-P Fitting Parameters for EABF } \\
\hline & & a & $\mathbf{b}$ & c & d & $X_{k}$ & a & $\mathbf{b}$ & c & d & $X_{k}$ \\
\hline 0.015 & 77.63 & 0.107 & 1.004 & 1.406 & 0.115 & 11.709 & 0.116 & 1.004 & 1.412 & 0.125 & 12.370 \\
\hline 0.020 & 79.52 & 0.114 & 2.367 & 1.791 & -0.141 & 12.991 & 0.072 & 1.200 & 1.823 & -0.070 & 17.463 \\
\hline 0.030 & 79.08 & 0.119 & 3.359 & 1.013 & -0.200 & 29.963 & 0.121 & 1.460 & 1.021 & -0.125 & 26.199 \\
\hline 0.040 & 73.97 & 0.089 & 3.883 & 0.465 & -0.047 & 23.838 & 0.104 & 1.516 & 0.469 & -0.042 & 21.650 \\
\hline 0.050 & 72.57 & -0.171 & 3.202 & 0.149 & -0.016 & 13.144 & -0.048 & 1.446 & 0.160 & 0.034 & 10.351 \\
\hline 0.060 & 71.14 & 0.786 & 2.559 & 0.069 & -0.122 & 14.007 & 0.553 & 1.395 & 0.089 & -0.122 & 16.666 \\
\hline 0.080 & 67.54 & 0.782 & 1.711 & 0.028 & -0.221 & 14.759 & 0.628 & 1.332 & 0.065 & -0.228 & 14.108 \\
\hline 0.100 & 75.87 & 0.123 & 1.731 & 0.728 & -0.093 & 16.645 & 0.129 & 1.757 & 0.703 & -0.096 & 16.788 \\
\hline 0.150 & 69.75 & 0.367 & 1.246 & 0.145 & -0.105 & 14.966 & 0.357 & 1.579 & 0.101 & -0.053 & 23.036 \\
\hline 0.200 & 62.70 & 0.339 & 1.155 & 0.257 & -0.192 & 13.712 & 0.622 & 1.519 & 0.078 & -0.299 & 13.938 \\
\hline 0.300 & 50.50 & 0.168 & 1.170 & 0.487 & -0.081 & 13.621 & 0.396 & 1.559 & 0.203 & -0.218 & 13.310 \\
\hline 0.400 & 42.55 & 0.124 & 1.232 & 0.599 & -0.065 & 14.142 & 0.296 & 1.674 & 0.323 & -0.186 & 13.705 \\
\hline 0.500 & 37.68 & 0.099 & 1.289 & 0.669 & -0.053 & 14.135 & 0.238 & 1.784 & 0.413 & -0.155 & 13.735 \\
\hline 0.600 & 34.62 & 0.081 & 1.331 & 0.718 & -0.044 & 13.699 & 0.167 & 1.700 & 0.533 & -0.106 & 13.577 \\
\hline 0.800 & 31.20 & 0.058 & 1.393 & 0.793 & -0.033 & 13.708 & 0.130 & 1.816 & 0.620 & -0.086 & 13.574 \\
\hline 1.000 & 29.43 & 0.043 & 1.427 & 0.848 & -0.028 & 13.382 & 0.107 & 1.855 & 0.685 & -0.077 & 13.527 \\
\hline 1.500 & 27.95 & 0.013 & 1.418 & 0.975 & -0.021 & 14.321 & 0.060 & 1.780 & 0.838 & -0.056 & 13.858 \\
\hline 2.000 & 28.34 & 0.006 & 1.436 & 1.015 & -0.020 & 13.371 & 0.064 & 1.778 & 0.845 & -0.069 & 13.432 \\
\hline 3.000 & 30.33 & 0.016 & 1.446 & 1.019 & -0.041 & 13.341 & 0.090 & 1.721 & 0.807 & -0.107 & 13.535 \\
\hline 4.000 & 32.59 & 0.030 & 1.443 & 0.998 & -0.054 & 13.736 & 0.103 & 1.626 & 0.791 & -0.121 & 13.866 \\
\hline 5.000 & 34.74 & 0.063 & 1.529 & 0.916 & -0.083 & 13.979 & 0.135 & 1.663 & 0.728 & -0.150 & 14.150 \\
\hline 6.000 & 36.68 & 0.070 & 1.573 & 0.912 & -0.088 & 14.163 & 0.136 & 1.653 & 0.737 & -0.150 & 14.297 \\
\hline 8.000 & 39.98 & 0.068 & 1.762 & 0.955 & -0.087 & 14.145 & 0.122 & 1.725 & 0.803 & -0.139 & 14.280 \\
\hline 10.000 & 42.58 & 0.034 & 1.843 & 1.115 & -0.058 & 14.000 & 0.081 & 1.707 & 0.958 & -0.105 & 14.108 \\
\hline 15.000 & 47.08 & 0.007 & 2.093 & 1.336 & -0.038 & 13.695 & 0.030 & 2.081 & 1.231 & -0.063 & 13.726 \\
\hline
\end{tabular}

Table 10. (EBF and EABF) G-P fitting coefficients (b, c, a, Xk and d) of LBi50Eu2 glass sample.

\begin{tabular}{|c|c|c|c|c|c|c|c|c|c|c|c|}
\hline \multirow{2}{*}{$\begin{array}{l}\text { Energy } \\
(\mathrm{MeV})\end{array}$} & \multirow{2}{*}{$\mathrm{Z}_{\mathrm{eq}}$} & \multicolumn{5}{|c|}{ G-P Fitting Parameters for EBF } & \multicolumn{5}{|c|}{ G-P Fitting Parameters for EABF } \\
\hline & & $\mathbf{a}$ & b & c & d & $X_{k}$ & a & $\mathbf{b}$ & c & d & $X_{k}$ \\
\hline 0.015 & 77.45 & 0.106 & 1.004 & 1.402 & 0.114 & 11.712 & 0.115 & 1.004 & 1.408 & 0.124 & 12.378 \\
\hline 0.020 & 79.39 & 0.115 & 2.364 & 1.788 & -0.143 & 12.987 & 0.072 & 1.200 & 1.819 & -0.071 & 17.452 \\
\hline 0.030 & 78.96 & 0.120 & 3.352 & 1.011 & -0.199 & 29.915 & 0.122 & 1.459 & 1.019 & -0.126 & 26.159 \\
\hline 0.040 & 73.91 & 0.089 & 3.886 & 0.457 & -0.046 & 23.815 & 0.104 & 1.515 & 0.462 & -0.042 & 21.728 \\
\hline 0.050 & 72.32 & -0.150 & 3.215 & 0.165 & -0.026 & 13.313 & -0.033 & 1.455 & 0.175 & 0.021 & 10.643 \\
\hline 0.060 & 70.94 & 0.746 & 2.577 & 0.077 & -0.119 & 13.573 & 0.523 & 1.403 & 0.097 & -0.114 & 16.884 \\
\hline 0.080 & 67.46 & 0.784 & 1.716 & 0.027 & -0.217 & 14.795 & 0.633 & 1.335 & 0.063 & -0.228 & 14.115 \\
\hline 0.100 & 75.79 & 0.122 & 1.731 & 0.725 & -0.092 & 16.663 & 0.128 & 1.757 & 0.700 & -0.095 & 16.799 \\
\hline 0.150 & 69.75 & 0.368 & 1.246 & 0.146 & -0.107 & 14.958 & 0.359 & 1.578 & 0.101 & -0.055 & 22.973 \\
\hline 0.200 & 62.78 & 0.339 & 1.155 & 0.258 & -0.191 & 13.715 & 0.621 & 1.518 & 0.079 & -0.299 & 13.937 \\
\hline 0.300 & 50.67 & 0.168 & 1.171 & 0.488 & -0.081 & 13.622 & 0.395 & 1.560 & 0.204 & -0.218 & 13.311 \\
\hline 0.400 & 42.76 & 0.123 & 1.232 & 0.600 & -0.065 & 14.142 & 0.296 & 1.675 & 0.324 & -0.186 & 13.706 \\
\hline 0.500 & 37.90 & 0.099 & 1.289 & 0.670 & -0.053 & 14.134 & 0.238 & 1.785 & 0.414 & -0.154 & 13.736 \\
\hline 0.600 & 34.85 & 0.081 & 1.332 & 0.719 & -0.044 & 13.698 & 0.167 & 1.702 & 0.534 & -0.106 & 13.577 \\
\hline 0.800 & 31.43 & 0.058 & 1.394 & 0.793 & -0.033 & 13.708 & 0.130 & 1.818 & 0.621 & -0.086 & 13.575 \\
\hline 1.000 & 29.66 & 0.043 & 1.428 & 0.848 & -0.028 & 13.378 & 0.107 & 1.857 & 0.685 & -0.077 & 13.528 \\
\hline 1.500 & 28.19 & 0.013 & 1.418 & 0.975 & -0.021 & 14.317 & 0.060 & 1.781 & 0.838 & -0.056 & 13.857 \\
\hline 2.000 & 28.58 & 0.006 & 1.436 & 1.016 & -0.020 & 13.370 & 0.064 & 1.778 & 0.845 & -0.069 & 13.432 \\
\hline 3.000 & 30.58 & 0.016 & 1.447 & 1.019 & -0.041 & 13.341 & 0.090 & 1.721 & 0.807 & -0.107 & 13.535 \\
\hline 4.000 & 32.83 & 0.030 & 1.443 & 0.998 & -0.054 & 13.736 & 0.103 & 1.626 & 0.791 & -0.121 & 13.866 \\
\hline 5.000 & 34.99 & 0.063 & 1.528 & 0.917 & -0.083 & 13.979 & 0.135 & 1.662 & 0.728 & -0.150 & 14.150 \\
\hline 6.000 & 36.94 & 0.070 & 1.572 & 0.912 & -0.088 & 14.163 & 0.136 & 1.651 & 0.737 & -0.150 & 14.297 \\
\hline 8.000 & 40.22 & 0.068 & 1.761 & 0.955 & -0.087 & 14.144 & 0.122 & 1.723 & 0.803 & -0.139 & 14.280 \\
\hline 10.000 & 42.82 & 0.034 & 1.842 & 1.115 & -0.059 & 13.999 & 0.081 & 1.704 & 0.958 & -0.105 & 14.109 \\
\hline 15.000 & 47.29 & 0.007 & 2.091 & 1.337 & -0.038 & 13.695 & 0.029 & 2.083 & 1.233 & -0.062 & 13.725 \\
\hline
\end{tabular}


In Figure $9, \Sigma_{R}$ values of both groups of glasses are established. In both glass systems, the $\Sigma_{R}$ values decreased as the density decreased with the addition of $\mathrm{Eu}_{2} \mathrm{O}_{3}$. The $\Sigma_{R}$ values of LPb50BEu glasses were $0.10106 \mathrm{~cm}^{-1}, 0.09999 \mathrm{~cm}^{-1}, 0.09478 \mathrm{~cm}^{-1}$, and $0.09286 \mathrm{~cm}^{-1}$, respectively, while, for LBi50BEu glasses, they were found to be $0.11484 \mathrm{~cm}^{-1}, 0.11428 \mathrm{~cm}^{-1}$, $0.09745 \mathrm{~cm}^{-1}$, and $0.09921 \mathrm{~cm}^{-1}$. It appears that the LBi50BEu glass system is more effective at capturing neutrons than others. It is clear that selected glass systems are also successful at reducing neutrons when compared to water and paraffin $\left(\Sigma_{R}=0.101 \mathrm{~cm}^{-1}\right)$, which are traditional neutron moderators. As the charged particle moves through the material, it interacts with the atomic electrons in the material and its energy decreases. However, during this time, the stopping power increases because the kinetic energy of the particle is inversely proportional to the stopping power. The change of the mass stopping power (AMSP and PMSP) of $\mathrm{L}(\mathrm{Pb} / \mathrm{Bi}) 50 \mathrm{BEu}$ glasses versus the photon energy for alpha and proton particles is given in Figure 10. While the charged particles move in the glass in the form of a Bragg curve, and the curve increases proportionally with $1 / \mathrm{E}$, there is a sharp decrease in the curve at the end of the path where the particle travels through the matter. Since alpha particles are heavier than protons, they have reached the maximum MSP at higher energies. Since the stopping power of the material is proportional to the square of the atomic number, LBi50BEu glasses with larger $Z_{\text {eff }}$ values have higher MSP values. The furthest distance that the charged particles can travel through the material is expressed as the projected range (PR). Figure 11 presents the change of APR and PPR values of $\mathrm{L}(\mathrm{Pb} / \mathrm{Bi}) 50 \mathrm{BEu}$ glasses in response to kinetic energy. Since the addition of $\mathrm{Eu}_{2} \mathrm{O}_{3}$ reduces the $\mathrm{Z}_{\text {eff }}$ values, $\mathrm{PR}$ is larger in glasses with $2 \mathrm{~mol} \% \mathrm{Eu}_{2} \mathrm{O}_{3}$ added. Since protons are smaller in mass, they move faster and have a longer range inside the glass (PPR $>$ APR). The PRs of alpha and proton particles are shorter in LBi50BEu glasses.
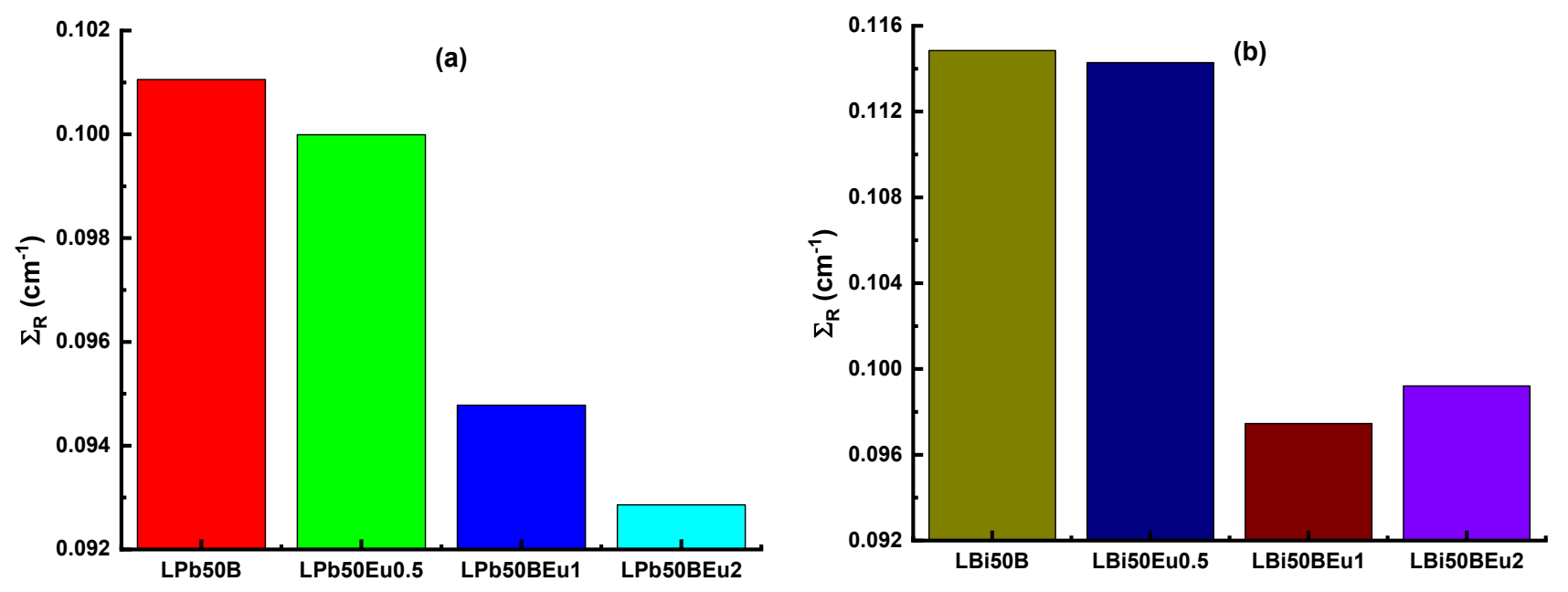

Figure 9. Effective removal cross-sections for fast neutrons $\left(\Sigma_{R}\right)$ for (a) LPb50BEu and (b) LBi50BEu glasses. 

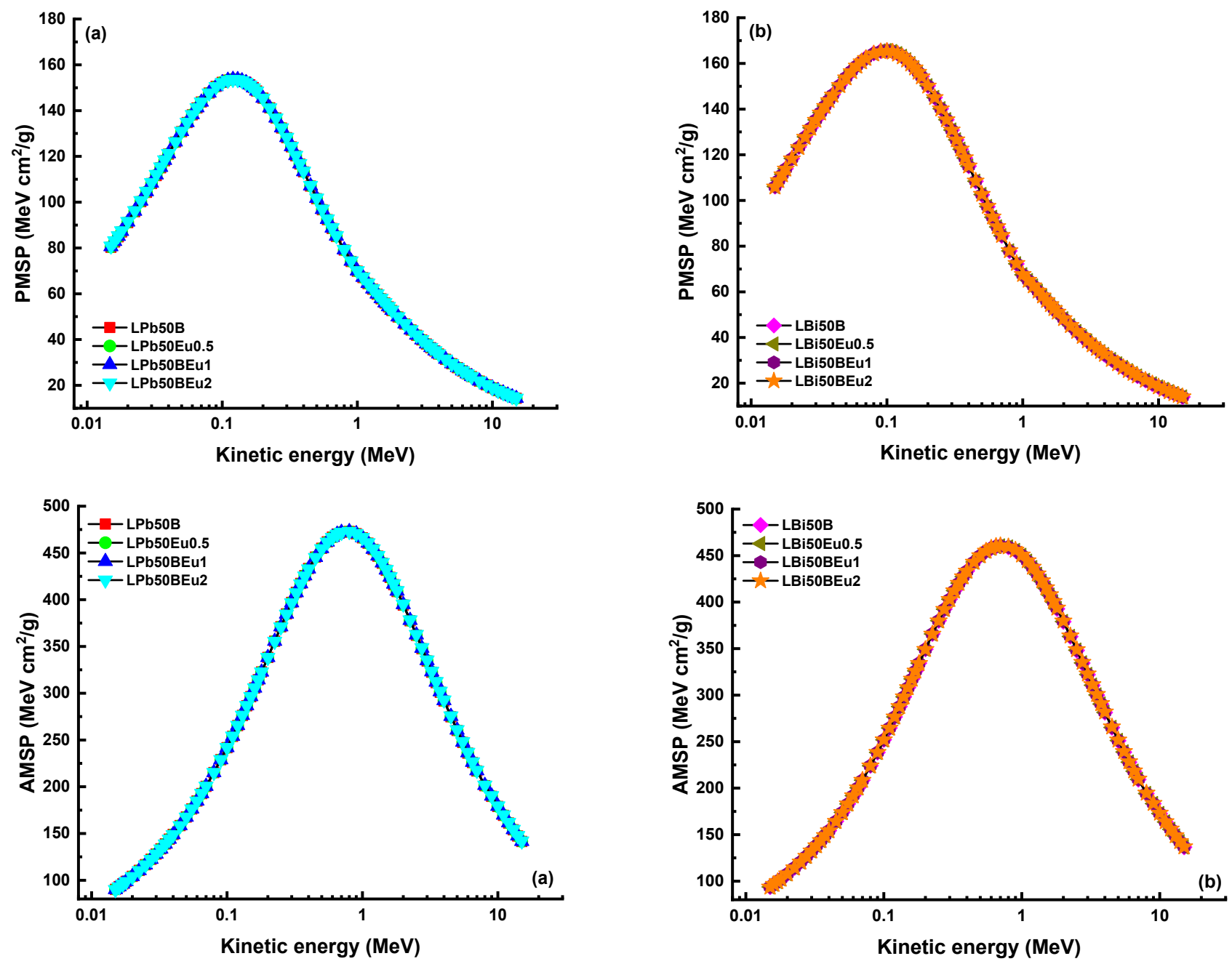

Figure 10. Proton (PMSP) and alpha (AMSP) mass stopping as a function of kinetic energy for (a) LPb50BEu and (b) LBi50BEu glasses.

Finally, it is worth noting that the linear attenuation coefficients determined using Phy-X/PSD and MCNPX (2.7.0) were very consistent. Figure 12 depicts a comparison of obtained linear attenuation coefficients from MCNPX Monte Carlo code and Phy-X/PSD for the LBi50B sample. A relative difference of $2 \%$ was reported at $0.02 \mathrm{MeV}$ photon energy. Overall, our findings showed that relative differences were varied from $1.15 \%$ to $2.6 \%$ at all photon energies. Both outcomes were reported in comparable linear attenuation coefficient values, based on our results. However, minor variations in certain energy areas were discovered. This is closely linked to the tools employed, since MCNPX is a Monte-Carlobased technique for radiation transport that needs user specification at different stages of the process described before. By contrast, Phy-X/PSD is a web-based tool that requires just the material composition, density, and energy quantities. As a result, some differences are almost certainly due to a variety of variables, including the number of dispersed gamma rays entering the detecting field, the narrow beam shape, the cross-section libraries and physics lists, the hardware performance, and the CPU characteristics of the computers used. 

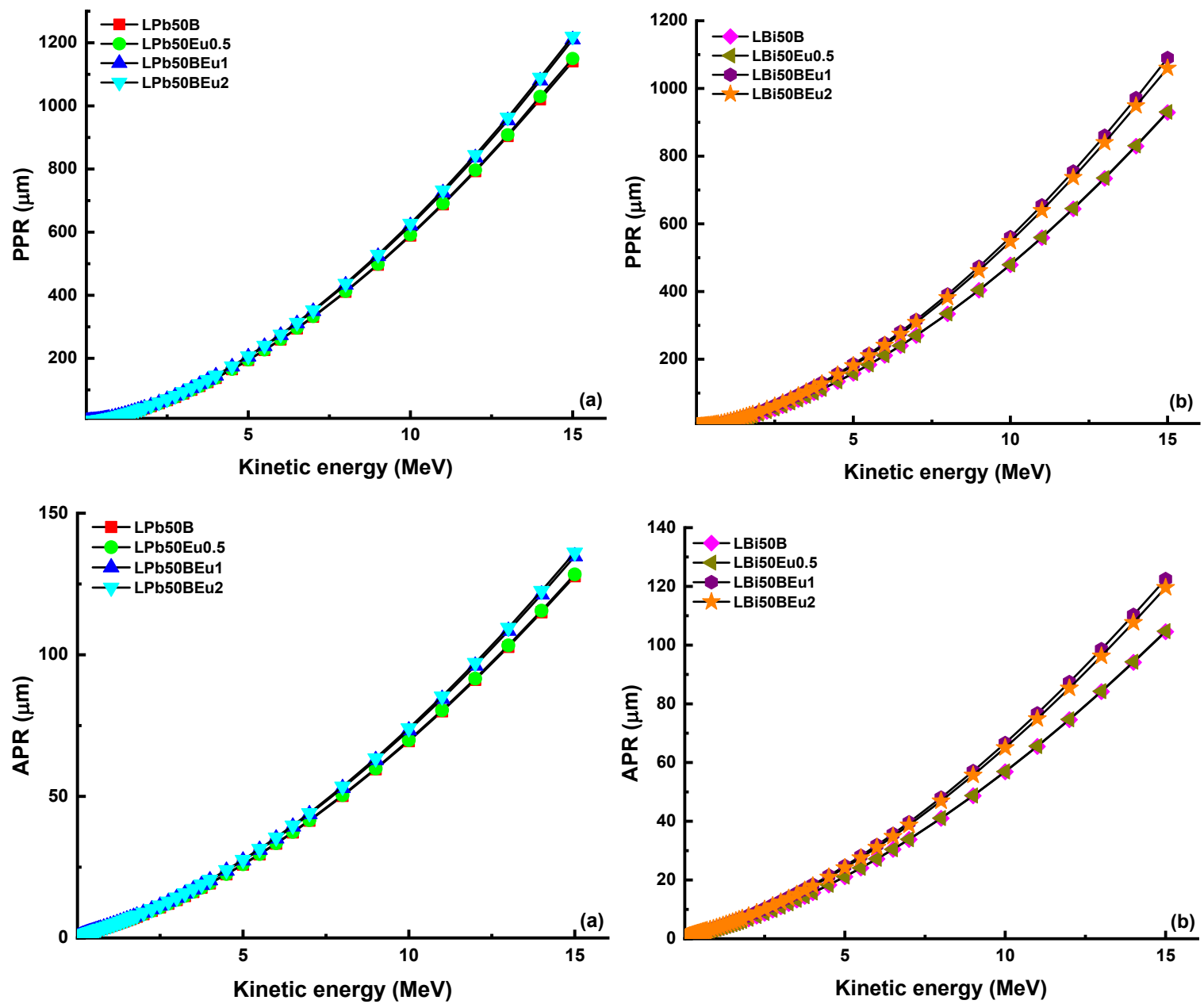

Figure 11. Proton (PPR) and alpha (APR) projected range as a function of kinetic energy for (a) LPb50BEu and (b) LBi50BEu glasses.

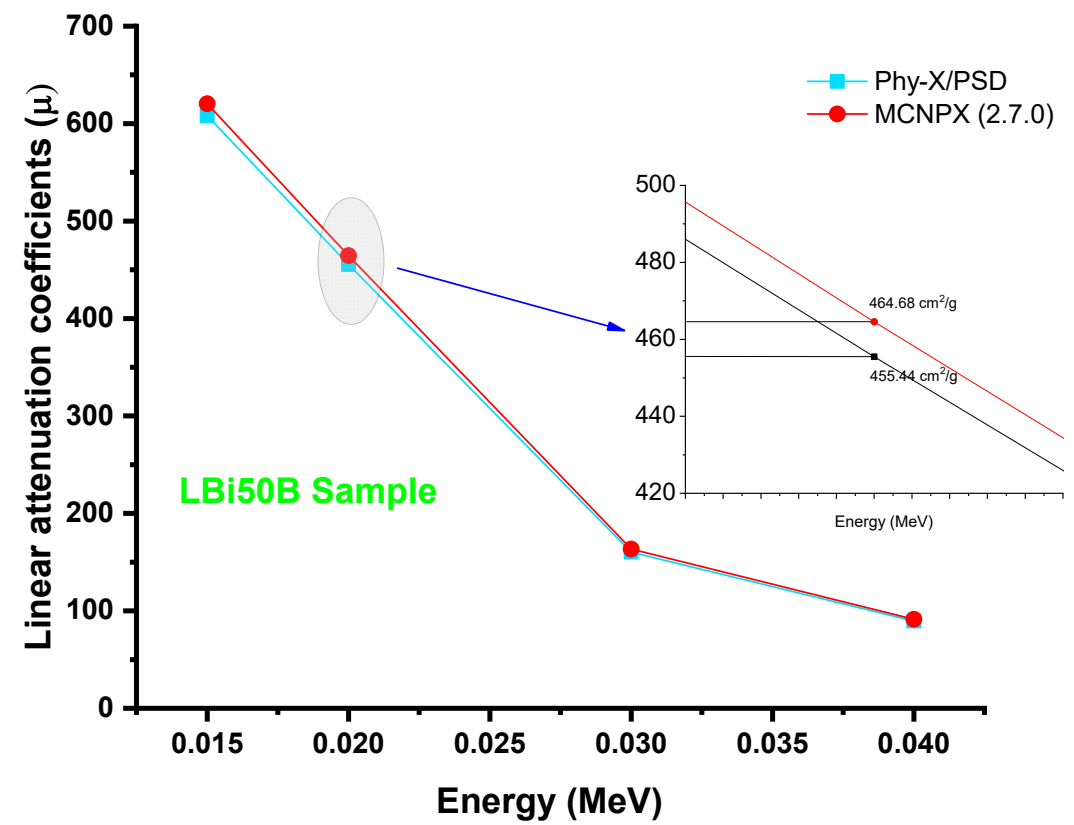

Figure 12. Comparison of obtained linear attenuation coefficients from MCNPX Monte Carlo code and Phy-X/PSD. 


\section{Conclusions}

In this study, the nuclear radiation shielding capabilities were thoroughly examined for eight borate glasses of Eu2O3 containing high ratios of $\mathrm{PbO} / \mathrm{Bi} 2 \mathrm{O} 3$. For this aim, MAC values of the glasses, encoded LPb50BEu and LBi50BEu, in the $0.015-15 \mathrm{MeV}$ photon energy range were acquired by MCNPX simulation codes and Phy-X/PSD online software. While the MAC values for $\mathrm{LPb} 50 \mathrm{BEu} 2$ and $\mathrm{LBi50Eu} 2$ glasses produced values of between $79.045 \mathrm{~cm}^{2} / \mathrm{g}-0.045 \mathrm{~cm}^{2} / \mathrm{g}$ and $89.442 \mathrm{~cm}^{2} / \mathrm{g}-0.048 \mathrm{~cm}^{2} / \mathrm{g}$, the MAC values of LPb50B and LBi50B glasses change between $78.429 \mathrm{~cm}^{2} / \mathrm{g}-0.045 \mathrm{~cm}^{2} / \mathrm{g}$ and $89.281 \mathrm{~cm}^{2} / \mathrm{g}-0.048 \mathrm{~cm}^{2} / \mathrm{g}$. Based on the MAC values, other vital photon-shielding parameters, $\mathrm{T}_{1 / 2}, \lambda, Z_{\text {eff, }} \mathrm{EABF}$, and EBF, were also found for LPb50BEu and LBi50BEu glasses. When all parameters were evaluated, it was revealed that the LBi50BEu glass system was more effective than LPb50BEu in shielding gamma radiation. It was seen that the $\Sigma_{R}$ values of both glass systems were greater than conventional neutron moderators. LBi50BEu2 glass was also found to be superior to LPb50BEu2 glass in stopping charged particle radiation, as in gamma radiation.

Author Contributions: Conceptualisation, G.A., H.O.T., H.M.H.Z., and S.A.M.I.; methodology, G.B. and H.O.T.; software, H.O.T., H.M.H.Z., and A.E.; validation, S.A.M.I., E.K., and A.E.; formal analysis, H.M.H.Z. and G.B.; investigation, H.O.T.; resources, G.B. and E.K.; data curation, S.A.M.I. and A.E.; writing—original draft preparation, H.O.T., G.B., and E.K.; writing—review and editing, H.M.H.Z., S.A.M.I., and A.E.; visualization, E.K.; supervision, H.M.H.Z. and E.K.; project administration, H.O.T. and S.A.M.I.; funding acquisition A.E. All authors have read and agreed to the published version of the manuscript.

Funding: This research was funded by the Deanship of Scientific Research at Princess Nourah bint Abdulrahman University through the Fast-track Research Funding Program. The APC was covered by "Dunarea de Jos" University of Galati, Romania.

Institutional Review Board Statement: Not applicable.

Informed Consent Statement: Not applicable.

Data Availability Statement: The data presented in this study are available on request from the corresponding author.

Acknowledgments: This research was funded by the Deanship of Scientific Research at Princess Nourah bint Abdulrahman University through the Fast-track Research Funding Program.

Conflicts of Interest: The authors declare no conflict of interest.

\section{References}

1. Mann, K.; Heer, M.S.; Rani, A. Effect of low-Z absorber's thickness on gamma-ray shielding parameters. Nucl. Instrum. Methods Phys. Res. Sect. A Accel. Spectrom. Detect. Assoc. Equip. 2015, 797, 19-28. [CrossRef]

2. Gardner, D.; Lark, R.; Jefferson, A.; Davies, R. A survey on problems encountered in current concrete construction and the potential benefits of self-healing cementitious materials. Case Stud. Constr. Mater. 2018, 8, 238-247. [CrossRef]

3. Sathiyapriya, G.; Naseer, K.A.; Marimuthu, K.; Kavaz, E.; Alalawi, A.; Al-Buriahi, M.S. Structural, optical and nuclear radiation shielding properties of strontium barium borate glasses doped with dysprosium and niobium. J. Mater. Sci. Mater. Electron. 2021, 32, 8570-8592. [CrossRef]

4. Salama, E.; Maher, A.; Youssef, G. Gamma radiation and neutron shielding properties of transparent alkali borosilicate glass containing lead. J. Phys. Chem. Solids 2019, 131, 139-147. [CrossRef]

5. Bagheri, R.; Adeli, R. Gamma-ray shielding properties of phosphate glasses containing $\mathrm{Bi} 2 \mathrm{O} 3, \mathrm{PbO}$, and $\mathrm{BaO}$ in different rates. Radiat. Phys. Chem. 2020, 174, 108918. [CrossRef]

6. Bhogi, A.; Kumar, R.V.; Kistaiah, P. Effect of alkaline earths on spectroscopic and structural properties of Cu2+ ions-doped lithium borate glasses. J. Noncryst. Solids 2015, 426, 47-54. [CrossRef]

7. Issever, U.; Kilic, G.; Ilik, E. The impact of $\mathrm{CuO}$ on physical, structural, optical and thermal properties of dark VPB semiconducting glasses. Opt. Mater. 2021, 116, 111084. [CrossRef]

8. Mostafa, A.; Zakaly, H.M.; Al-Ghamdi, S.; Issa, S.A.; Al-Zaibani, M.; Ramadan, R.; El Agammy, E. PbO-Sb $\mathrm{Sb}_{2}-\mathrm{O}_{2} \mathrm{O}_{3}-\mathrm{CuO}$ glassy system: Evaluation of optical, gamma and neutron shielding properties. Mater. Chem. Phys. 2021, 258, 123937. [CrossRef]

9. Tekin, H.; Kassab, L.; Issa, S.A.; Martins, M.; Bontempo, L.; Mattos, G.R.D.S. Newly developed BGO glasses: Synthesis, optical and nuclear radiation shielding properties. Ceram. Int. 2020, 46, 11861-11873. [CrossRef] 
10. Agar, O.; Kavaz, E.; Altunsoy, E.; Kilicoglu, O.; Tekin, H.; Sayyed, M.; Erguzel, T.; Tarhan, N. $\operatorname{Er}_{2} \mathrm{O}_{3}$ effects on photon and neutron shielding properties of $\mathrm{TeO}_{2}-\mathrm{Li}_{2} \mathrm{O}-\mathrm{ZnO}-\mathrm{Nb}_{2} \mathrm{O}_{5}$ glass system. Results Phys. 2019, 13, 102277. [CrossRef]

11. R.S.I.C.C. Collection, MCNPX User's Manual Version 2.4.0. Monte Carlo N-Particle Transport Code System for Multiple and High Energy Applications. 2002. Available online: http:/ / www.nea.fr/abs/html/ccc-0715.html (accessed on 6 July 2021).

12. Şakar, E.; Özpolat, Ö.F.; Alım, B.; Sayyed, M.; Kurudirek, M. Phy-X/PSD: Development of a user friendly online software for calculation of parameters relevant to radiation shielding and dosimetry. Radiat. Phys. Chem. 2020, 166, 108496. [CrossRef]

13. Ramesh, P.; Hegde, V.; Pramod, A.; Eraiah, B.; Rao, S.V.; Shisina, S.; Das, S.; Agarkov, D.; Eliseeva, G.; Jagannath, G.; et al. Effect of $\mathrm{Eu}^{3+}$ in tuning the ultrafast third-order optical nonlinearity in heavy metal borate glasses. Opt. Mater. 2020, 108, 110051. [CrossRef]

14. Gowda, S.; Krishnaveni, S.; Yashoda, T.; Umesh, T.K.; Gowda, R. Photon mass attenuation coefficients, effective atomic numbers and electron densities of some thermoluminescent dosimetric compounds. Pramana 2004, 63, 529-541. [CrossRef]

15. Ziegler, J.F.; Ziegler, M.; Biersack, J. SRIM-The stopping and range of ions in matter. Nucl. Instrum. Methods Phys. Res. Sect. B Beam Interact. Mater. Atoms 2010, 268, 1818-1823. [CrossRef]

16. Perişanoğlu, U. Assessment of nuclear shielding and alpha/proton mass stopping power properties of various metallic glasses. Appl. Phys. A 2019, 125, 801. [CrossRef]

17. Schott. 2018. Available online: http://www.schott.com/advanced_optics/english/products/opticalmaterials/special-materials/ radiation-shielding-glasses/index.html; http://www.schott.com/advanced_optics/english/products/opticalmaterials/\%0 Aspecial-mate (accessed on 3 September 2018).

18. Bashter, I. Calculation of radiation attenuation coefficients for shielding concretes. Ann. Nucl. Energy 1997, $24,1389-1401$. [CrossRef]

19. Oto, B.; Oto, G.; Madak, Z.; Kavaz, E. The interaction of gamma radiation with drugs used in cholinergic medications. Int. J. Radiat. Biol. 2019, 96, 236-244. [CrossRef] [PubMed]

20. Yorgun, N.Y.; Kavaz, E. Gamma photon protection properties of some cancer drugs for medical applications. Results Phys. 2019, 13, 102150. [CrossRef] 